\title{
Femtosecond laser-induced transformations in ultra-low expansion glass: Microstructure and local density variations by vibrational spectroscopy
}

\author{
I. Efthimiopoulos, D. Palles, S. Richter, U. Hoppe, D. Möncke, L. Wondraczek, S. Nolte, and E. I. Kamitsos
}

Citation: Journal of Applied Physics 123, 233105 (2018); doi: 10.1063/1.5030687

View online: https://doi.org/10.1063/1.5030687

View Table of Contents: http://aip.scitation.org/toc/jap/123/23

Published by the American Institute of Physics

\section{Articles you may be interested in}

Refractive index sensing using a light trapping cavity: A theoretical study

Journal of Applied Physics 123, 233103 (2018); 10.1063/1.5029233

High intensity, macroparticle-free, aluminum ion beam formation

Journal of Applied Physics 123, 233301 (2018); 10.1063/1.5034082

$3 \mathrm{D}$ simulation of superconducting magnetic shields and lenses using the fast Fourier transform Journal of Applied Physics 123, 233901 (2018); 10.1063/1.5027592

Ultrathin acoustic metasurfaces for reflective wave focusing

Journal of Applied Physics 123, 234501 (2018); 10.1063/1.5031482

Effects of stress on neighboring laser written waveguides in gallium lanthanum sulfide Applied Physics Letters 112, 111908 (2018); 10.1063/1.5018646

Saturable absorption by carbon nanotubes on silica microtoroids Journal of Applied Physics 123, 233104 (2018); 10.1063/1.5025885

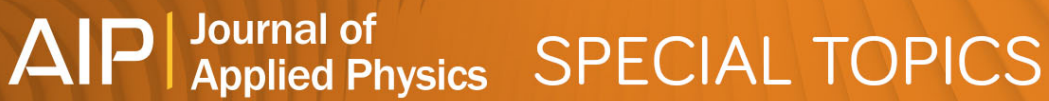

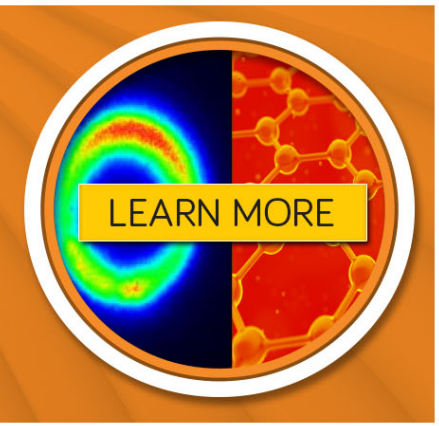




\title{
Femtosecond laser-induced transformations in ultra-low expansion glass: Microstructure and local density variations by vibrational spectroscopy
}

\author{
I. Efthimiopoulos, ${ }^{1, a)}$ D. Palles, ${ }^{1}$ S. Richter, ${ }^{2, b)}$ U. Hoppe, ${ }^{3}$ D. Möncke, ${ }^{1, c)}$ L. Wondraczek, ${ }^{4}$ \\ S. Nolte, ${ }^{2,5}$ and E. I. Kamitsos ${ }^{1, d)}$ \\ ${ }^{1}$ Theoretical and Physical Chemistry Institute, National Hellenic Research Foundation, \\ 48 Vassileos Constantinou Avenue, 11635 Athens, Greece \\ ${ }^{2}$ Institute of Applied Physics, Abbe Center of Photonics, Friedrich-Schiller-Universität Jena, \\ Max-Wien-Platz 1, 07743 Jena, Germany \\ ${ }^{3}$ Insitute of Physics, Universität Rostock, Albert-Einstein-Strasse 23, 18051 Rostock, Germany \\ ${ }^{4}$ Otto Schott Institute of Materials Research, Friedrich-Schiller-Universität Jena, Fraunhoferstrasse 6, \\ 07743 Jena, Germany \\ ${ }^{5}$ Fraunhofer Institute for Applied Optics and Precision Engineering, Albert-Einstein-Strasse 7, 07745 Jena, \\ Germany
}

(Received 24 March 2018; accepted 29 May 2018; published online 19 June 2018)

\begin{abstract}
We report X-ray diffraction, resonance Raman, and infrared (IR) results on pristine ultra-low expansion (ULE) glass, a binary titanosilicate glass with $5.67 \mathrm{~mol} \% \mathrm{TiO}_{2}$. ULE processing by femtosecond (fs) laser radiation leads to nanograting writing and photo-darkening for imaging and data storage. We investigate here the vibrational/structural changes induced by fs laser irradiation of ULE at $515 \mathrm{~nm}$. Optical imaging revealed the formation of micro-cavities, and Raman mapping showed molecular oxygen trapped in such cavities of laser-irradiated ULE glass. While titanium in the pristine glass was found predominantly in tetrahedral $\mathrm{Ti}^{4+}$ sites highly dispersed in the silicate matrix, Raman and IR reflectance spectroscopy on laser-irradiated ULE indicated the formation of $\mathrm{Ti}^{3+}$ sites; $\mathrm{Ti}^{3+}$ octahedral sites are formed in the shells of cavities and aggregate in amorphous $\mathrm{Ti}_{2} \mathrm{O}_{3}$-type clusters, while the glass around and below cavities contains $\mathrm{Ti}^{3+}$ tetrahedral sites dispersed in the silicate network. Laser-processed ULE glass was found to also exhibit local restructuring of the silicate matrix. Shifts of the strong IR band at about $1080-1100 \mathrm{~cm}^{-1}$ were translated into changes of the average Si-O-Si bond angle in the laser-transformed areas and found to reflect local density variations; the average local density increases relative to silica glass up to about $8 \%$ in the shells of micro-cavities and decreases by about $0.5 \%$ in the surrounding material. Chemical processes were proposed to account for photo-darkening and the local structural transformation effect in the probed areas of the fs laser-processed ULE glasses. Published by AIP Publishing.

https://doi.org/10.1063/1.5030687
\end{abstract}

\section{INTRODUCTION}

Binary titanosilicate glasses in the system of $\mathrm{xTiO}_{2^{-}}$ $(1-\mathrm{x}) \mathrm{SiO}_{2}$ have found a variety of applications in areas such as optics and catalysis. ${ }^{1-4}$ To reveal the role of titanium in the structure and the physical properties of such materials, early investigations by Extended X-ray Absorption Fine Structure $(\mathrm{EXAFS})^{5}$ and X-ray Absorption Near Edge Structure (XANES), ${ }^{6}$ showed that Ti occupies rutile-like octahedral sites in glasses prepared by flame hydrolysis and containing less than 0.04 mol. $\% \mathrm{TiO}_{2}$. A two-site model was found appropriate for glasses having higher $\mathrm{TiO}_{2}$ contents, with Ti occupying mostly tetrahedral sites.

$\mathrm{X}$-ray emission spectroscopy on rf-sputtered amorphous $\mathrm{TiO}_{2}-\mathrm{SiO}_{2}$ films showed that, while $\mathrm{Si}$ ions are always in tetrahedral coordination, the coordination number of $\mathrm{Ti}$ ions

\footnotetext{
a) Current address: Helmholtz-Zentrum Potsdam, Deutsches GeoForschungsZentrum GFZ, Telegrafenberg, 14473 Potsdam, Germany.

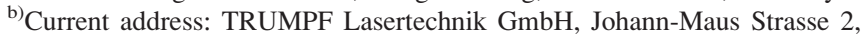
71254 Ditzingen, Germany.

${ }^{c}$ Current address: Department of Built Environment and Energy Technology, Linnaeus University, 35195 Växjö, Sweden.

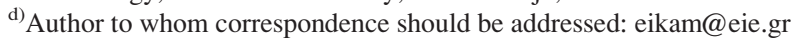

may change from 4 to $6 .{ }^{7}$ Most Ti ions are in tetrahedral sites for contents below ca. $15 \mathrm{~mol} \% \mathrm{TiO}_{2}$, but the fraction of tetrahedral sites decreases in favor of octahedral sites with increasing $\mathrm{TiO}_{2}$ content up to ca. $40 \mathrm{~mol}$. \%, with the latter sites being the only ones present at higher $\mathrm{TiO}_{2}$ concentration. ${ }^{7}$ Glasses in the $\mathrm{TiO}_{2}-\mathrm{SiO}_{2}$ system were also prepared by the sol-gel method and the coordination of Ti was investigated by EXAFS and XANES spectroscopies. ${ }^{8}$ Contrary to previous studies, ${ }^{5,6} \mathrm{Ti}$ was suggested to occupy only tetrahedral sites in glasses with compositions lower than $15 \mathrm{~mol} \%$ $\mathrm{TiO}_{2}$. Similar propositions were made for titanium-silicon oxide catalysts prepared by the sol-gel method; titanium oxide species were proposed to be highly dispersed in the $\mathrm{SiO}_{2}$ matrix and exist only in tetrahedral coordination for $\mathrm{TiO}_{2}$ content up to ca. 43 mol. \%. ${ }^{9}$

An important example of binary titanosilicate glasses is the Ultra-Low Expansion glass (ULE ${ }^{\circledR}$, Corning). It comprises a $\mathrm{TiO}_{2}$ fraction of $7.4 \mathrm{wt}$. \% (5.67 mol. \%) and exhibits an almost zero coefficient of thermal expansion (CTE) near room temperature, i.e., a mean CTE of $0 \pm 30 \mathrm{ppb} /{ }^{\circ} \mathrm{C}$ from $5^{\circ} \mathrm{C}$ to $35^{\circ} \mathrm{C}$, significantly lower than the silica benchmark materials. ${ }^{10}$ This property has made ULE glass an important 
material for applications requiring geometrical stability at ambient temperature, like substrates and masks or mirror blanks. It has also been shown that laser inscription of ULE glass can lead to the formation of nanogratings, ${ }^{11,12}$ thus enabling its use for optical and imaging operations. ${ }^{13,14}$

However, during laser processing and nanograting formation, the laser interaction with ULE glass can cause local melting and darkening depending on the laser irradiation parameters. ${ }^{12,15,16}$ Regarding darkening, UV-Vis absorption and electron spin resonance (ESR) spectra of laser-processed ULE glasses suggested the presence of trivalent Ti-ions; most probably generated through a photo-reduction of $\mathrm{Ti}^{4+}$ to $\mathrm{Ti}^{3+}$ upon irradiation. ${ }^{12}$ The ability to tune the absorption of glass by controlling its photo-darkening increases the data storage capability of ULE glass by at least a factor of $10{ }^{12}$ In addition, when the laser intensity is high enough, local micro-explosions within the bulk of the glass can produce micropores or cavities. Furthermore, heat accumulation may occur if the time between the laser pulses is shorter than the heat dissipation time. Under these circumstances, the material may be locally molten and this may lead to local rearrangements of the network structure upon re-solidification.

Following our preliminary work, ${ }^{12}$ the motivation of the present infrared and Raman spectroscopic study is to elucidate in-depth the vibrational and structural changes induced in ULE glass by fs laser irradiation. To this aim, we first present and discuss the results of $\mathrm{X}$-ray diffraction on pristine ULE glass in comparison to the well-studied vitreous silica, $\mathrm{v}-\mathrm{SiO}_{2}$. The results of the $\mathrm{X}$-ray study regarding the coordination states and bond lengths of the Ti-oxygen and $\mathrm{Si}$ oxygen polyhedra are essential for assigning the IR and Raman vibrational bands of pristine ULE. Besides structural transformations of the silicate matrix by laser irradiation, we focus on manifestations in the vibrational spectra of the change in the oxidation state of titanium from $\mathrm{Ti}^{4+}$ to $\mathrm{Ti}^{3+}$. We are able to show that fs laser processing causes the formation of locally densified silicate structures mainly in shells of micro-cavities containing molecular oxygen, where $\mathrm{Ti}^{3+}$ octahedral sites are aggregated in amorphous $\mathrm{Ti}_{2} \mathrm{O}_{3}$-type clusters. Such densified areas are surrounded by the glassy material with lower average density and with $\mathrm{Ti}^{3+}$ ions in tetrahedral sites dispersed in the silicate matrix. The results of this study are discussed in terms of chemical reactions which account for the restructuring and change in connectivity of the silicate network and for the reduction of $\mathrm{Ti}^{4+}$ to $\mathrm{Ti}^{3+}$ caused by fs laser irradiation.

\section{EXPERIMENTAL METHODS}

\section{A. Laser-processing of ULE glass}

Pristine ULE glass was purchased from Corning, Inc. (Corning code 7972). A fs oscillator (Amplitude Systems, t-Pulse 500) providing pulses of $450 \mathrm{fs}$ duration at a wavelength of $1030 \mathrm{~nm}$ and a repetition rate of $9.4 \mathrm{MHz}$ was used, and an LBO (lithium borate) crystal was employed to generate the second harmonic $(515 \mathrm{~nm})$ for laser-processing of ULE glasses. The repetition rate and pulse energies were varied by an external acousto-optic modulator and a halfwave plate followed by a polarizer, respectively. The laser pulses were focused onto the sample with an aspheric lens with a focal length of $4.5 \mathrm{~mm}$ (NA of 0.55 ). Thus, the calculated spot diameter is about one micrometer with the beam diameter before focusing being $3.8 \mathrm{~mm}$. These laser parameters correspond to irradiance in the range $4.2-5.5 \times 10^{13} \mathrm{~W} /$ $\mathrm{cm}^{2}$ or to laser fluence $19-25 \mathrm{~J} / \mathrm{cm}^{2}$ per pulse. In order to inscribe continuous lines, the ULE samples were translated with respect to the laser focus. To realize larger lasermodified areas in glass, parallel lines were inscribed with a line spacing of $20 \mu \mathrm{m}$ to produce inscribed areas of about $4 \times 4 \mathrm{~mm}^{2}$. Laser writing was done below the glass surface to avoid surface breakdown.

Previous studies have suggested that the laser-inscribed structures inside the glass consist of cavity-like inclusions in reversed-teardrop-like modified areas of the glass. ${ }^{12,17}$ These cavities are located in the upper part of the laser-modified zones, while the rest of the teardrop-like modifications consist of a laser-molten and resolidified glassy material. The pulse energy, repetition rate, and translation velocity of the sample influence the dimensions of the laser-inscribed structures. ${ }^{18}$

After laser-processing, the glass samples were polished to expose the laser-inscribed regions and, thus, facilitate their probing by IR reflectance and Raman spectroscopy. Polishing was followed by chemical etching to remove residues of polishing agents. Table I summarizes the laser-processing parameters, where the notations ULEc1, ULEc2, and ULEcf indicate ULE glasses treated with different laser processing parameters and, subsequently, with different extents of polishing to allow probing distinct parts of laser-inscribed areas. In particular, polishing of the ULEc1 and ULEc2 samples exposed near the surface areas containing cavities, whereas the exposed areas of ULEcf consist of the lower parts of the "teardrops" which are cavity-free, as shown by the optical microscopy images in Fig. 1. With the laser-processing parameters used here the written structures have widths of $15 \mu \mathrm{m}$ and are separated by $5 \mu \mathrm{m}$ interspacings. Figure 1 shows that the exposed written areas of ULEc1 and ULEc2 exhibit circular micro-cavities of 4-6 $\mu \mathrm{m}$ in diameter, with ULEc2 having a higher density of cavities. Polishing of ULEcf revealed well-defined written areas which, however, are free of cavities.

\section{B. X-ray diffraction measurements}

X-ray diffraction experiments were performed with synchrotron radiation at DESY, PETRA III, in Hamburg,

TABLE I. Laser-processing parameters of ULE glasses. For optical microscopy images of the spectroscopically probed areas of samples ULEc1, ULEc2, and ULEcf, see Fig. 1.

\begin{tabular}{lccc}
\hline \hline Processing parameters & ULEc1 & ULEc2 & ULEcf \\
\hline Average output power $(\mathrm{W})$ & 1.5 & 1.5 & 2 \\
Repetition rate $(\mathrm{MHz})$ & 9.4 & 9.4 & 9.4 \\
Pulse energy $(\mathrm{nJ})$ & 150 & 150 & 200 \\
Wavelength $(\mathrm{nm})$ & 515 & 515 & 515 \\
Focal length $(\mathrm{mm})$ & 4.5 & 4.5 & 4.5 \\
Translation velocity $(\mathrm{mm} / \mathrm{s})$ & 3 & 3 & 3 \\
Line spacing $(\mu \mathrm{m})$ & 20 & 20 & 20 \\
Number of planes & 6 & 11 & 9 \\
Plane distance $(\mu \mathrm{m})$ & 45 & 15 & 110 \\
\hline \hline
\end{tabular}




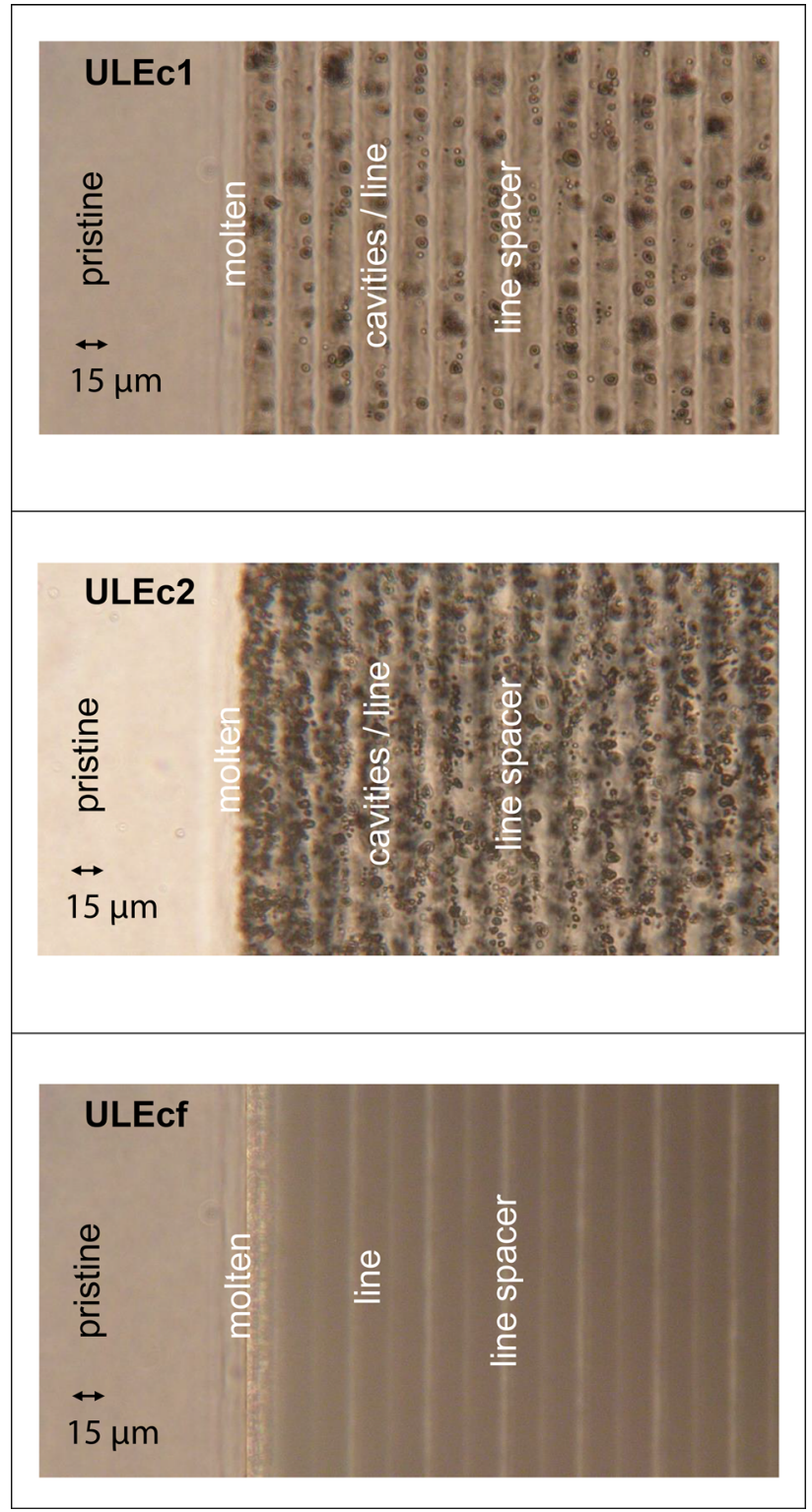

FIG. 1. Top-view optical microscopy images of fs laser-processed ULE glasses using the processing parameters specified in Table I. After laserprocessing, the glass samples were polished to a different extent and chemically etched to expose near the surface different areas of the fs-laser written structures. Polishing of samples ULEc1 and ULEc2 exposed the areas containing cavities to probing by spectroscopy, while the exposed areas for ULEcf are cavity-free.

Germany (beam line P02.1), with photon energies of $60 \mathrm{keV}$ and image plate detectors sensitive to energies higher than $20 \mathrm{keV}$ (Perkin-Elmer 1621). Calibration with $\mathrm{CeO}_{2}$ powder resulted in a radiation wavelength of $0.02080 \mathrm{~nm}$ and a sample-detector distance of $249.9 \mathrm{~mm}$. The beam size was $0.5 \times 0.5 \mathrm{~mm}^{2}$. The $0.3 \mathrm{~mm}$ thick and polished ULE sample plate was irradiated for about $10 \mathrm{~s}$ and the measurement was repeated five times. The complete two-dimensional scattering images could be merged to functions of the scattering angle, and the intensities were corrected for background scattering and absorption. The resulting functions were normalized to tabulated data of the atomic coherent and Compton scattering. After subtraction of the Compton scattering, the structure factors were obtained.

\section{Vibrational spectroscopy and optical measurements}

All spectroscopic measurements were performed at room temperature. Raman spectra were measured at the backscattering geometry on a Renishaw inVia confocal microscope using the excitation wavelengths $\lambda=325,488$, 514 , and $633 \mathrm{~nm}$, a 2400 lines/mm grating, $2 \mathrm{~cm}^{-1}$ resolution and spatial resolution better than $1 \mu \mathrm{m}$. Raman spectra were measured also on a Fourier-Transform (FT) Raman spectrometer (Bruker RFS 100 FT) with excitation $\lambda=1064 \mathrm{~nm}$ from a $\mathrm{Nd}$ :YAG laser and $4 \mathrm{~cm}^{-1}$ resolution.

The infrared spectra were measured on a vacuum Fourier transform spectrometer (Bruker, Vertex 80v) in the reflectance mode at nearly normal incidence $\left(11^{\circ}\right.$ off-normal), using an aperture of $3 \mathrm{~mm}$ in diameter. Each spectrum is the average of 200 scans taken at $2 \mathrm{~cm}^{-1}$ resolution. For each sample, measurements were done separately in the far- and mid-IR region and the two spectra were merged to form a continuous reflectance spectrum in the range $30-7000 \mathrm{~cm}^{-1}$.

Transmittance spectra in the UV-Vis range were recorded on a Perkin-Elmer Lambda 19 spectrophotometer. The measured transmittance spectra, $\mathrm{T}(\lambda)$, were converted to absorption coefficient spectra, $\alpha(\lambda),{ }^{19}$ using the expression

$$
\alpha(\lambda)=-\ln [\mathrm{T}(\lambda) / \mathrm{T}(1500)] / \mathrm{d},
$$

where $\mathrm{d}$ is the sample thickness and the transmittance $\mathrm{T}(\lambda)$ is normalized to the transmittance at $1500 \mathrm{~nm}$ to account for reflection losses.

\section{RESULTS AND DISCUSSION}

\section{A. Structure of pristine ULE glass}

We consider first the X-ray diffraction and vibrational spectroscopy on pristine ULE glass, as a necesssary tool for understanding the effects of fs laser irradiation on this glass.

\section{X-ray diffraction}

To the best of our knowledge, this is the first X-ray diffraction study on ULE glass. This lack of data may be due to the low concentration of titanium ions, which approaches the limit of sensitivity for X-ray diffraction. However, the high quality of our experimental data obtained at the DESY synchrotron facility, in combination with the well-defined ULE composition, allows for their meaningful and justified interpretation. The X-ray structure factor of ULE is compared in Fig. 2(a) with that of vitreous silica, $\mathrm{v}-\mathrm{SiO}_{2}$; the latter was obtained by $\mathrm{Ag} \mathrm{K}_{\alpha}$ radiation on a laboratory equipment. The comparison of the two functions suggests similar structures, i.e., the $\mathrm{v}-\mathrm{SiO}_{2}$ network character at the intermediaterange scale is not destroyed by the $5.67 \%$ of Ti-centered oxygen polyhedra. This similarity could be best realized with randomly dispersed Ti-oxygen polyhedral units in the silicate network and an average Ti-O coordination number close to four. Actually, this number is determined from the fits of the short-range order distances in the correlation function, $\mathrm{T}(\mathrm{r})$, which is obtained as Fourier transform of the 

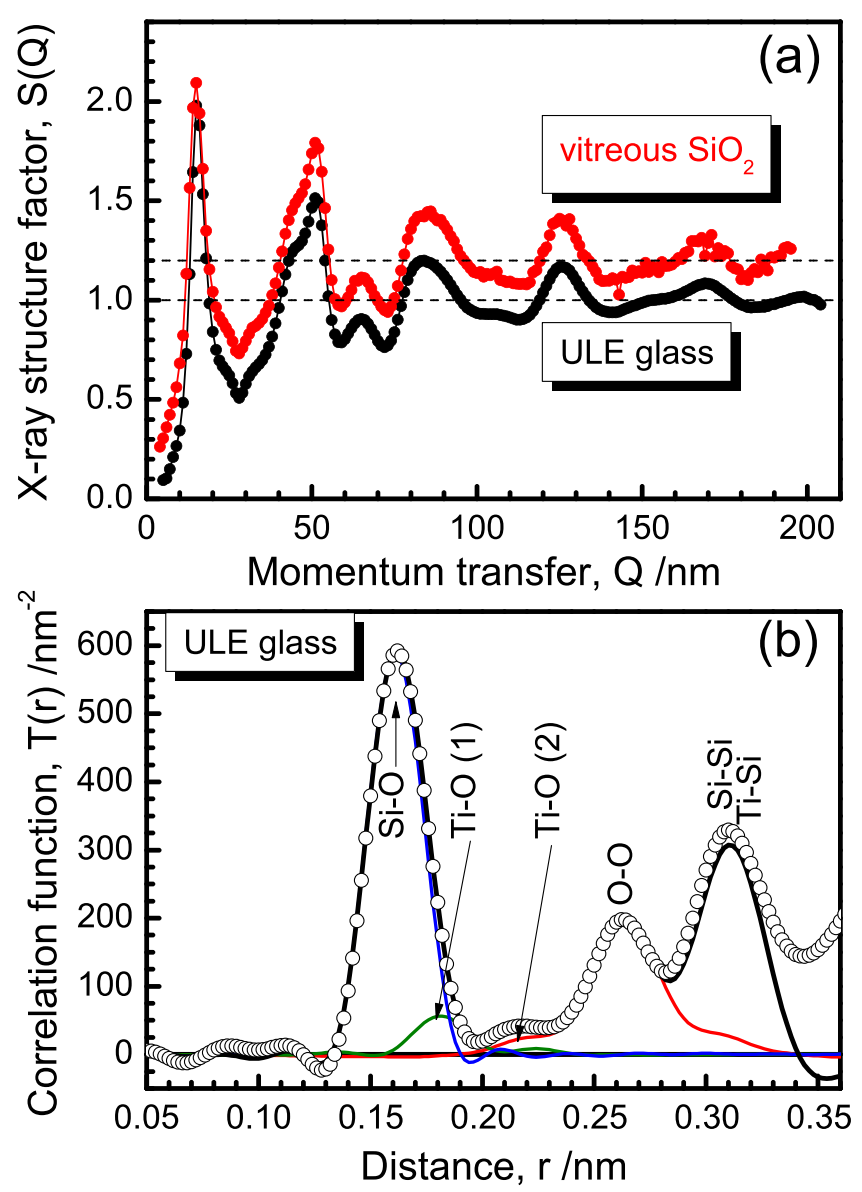

FIG. 2. (a) X-ray structure factor of ULE glass in comparison with that of vitreous $\mathrm{SiO}_{2}$. The $\mathrm{S}(\mathrm{Q})$ of the latter glass is shifted vertically for clarity and (b) total X-ray correlation function of ULE glass in the range of firstneighbor peaks; experimental data (open circles), model function (thick solid line), and separate pair peaks (thin-lined functions). Visible oscillation on the sides of the model peaks (Gaussian functions) are due to simulation of the termination effects and Q-dependent weighting factors of Fourier transform.

structure factor, $\mathrm{S}(\mathrm{Q})$, up to $\mathrm{Q}_{\max }$ of $204 \mathrm{~nm}^{-1}$ using a Lorch damping function.

The resulting $\mathrm{T}(\mathrm{r})$ function for ULE in Fig. 2(b) shows neither a separate peak nor clear shoulders for Ti-O distances; the $\mathrm{TiO}_{2}$ content is not enough to create a separate $\mathrm{Ti}-\mathrm{O}$ peak and/or such a peak overlaps with the Si-O peak. The Ti-O distances were determined from fits with several fixed parameters. Their choice was based on the following assumptions: (a) all silicate entities are $\mathrm{SiO}_{4}$ tetrahedra, with corresponding $\mathrm{Si}-\mathrm{O}$ bond lengths, and (b) the $\mathrm{SiO}_{4}$ tetrahedra have six O-O edges. Since there is no reason that single Gaussians are the best choice for fitting diffraction data, the intrinsic asymmetry of peaks might be adjusted by including a second weak peak, as was done for the $\mathrm{Si}-\mathrm{O}$ fit. The fact that the coordination number of $\mathrm{Si}, \mathrm{CN}(\mathrm{Si})$, was set at four results in an error-free value for the $\mathrm{Si}-\mathrm{O}$ bond length, which cannot be avoided since the $\mathrm{Si}-\mathrm{O}$ and Ti-O distances differ too slightly and the real-space deconvolution of the experiment $\left(Q_{\max }\right)$ is only moderate. The derived Si-O distance of $1.61 \AA$ (Table II) is in excellent agreement with findings on titanium-silicate glasses studied by Si K-edge X-ray absorption spectroscopy. ${ }^{20}$
TABLE II. Parameters of Gaussian functions of distances in the short-range order of ULE glass. The parameters with error bars were determined, while the others were fixed in the fits.

\begin{tabular}{lcccc}
\hline \hline Atom pair & $\begin{array}{c}\text { Number of } \\
\text { neighbors }\end{array}$ & $\begin{array}{c}\text { Distances } \\
(\AA)\end{array}$ & $\begin{array}{c}\text { Widths } \\
(\AA)\end{array}$ & Comments \\
\hline Si-O & 3.7 & $1.61 \pm 0.01$ & $0.11 \pm 0.01$ & \\
& 0.3 & 1.66 & 0.15 & \\
Ti-O & $4.1 \pm 0.6$ & $1.81 \pm 0.03$ & $0.12 \pm 0.02$ & \\
& $0.6 \pm 0.6$ & $2.17 \pm 0.05$ & $0.14 \pm 0.04$ & \\
O-O & 5.65 & $2.63 \pm 0.02$ & $0.21 \pm 0.03$ & $\mathrm{SiO}_{4}$ edges \\
& 0.35 & 2.87 & 0.25 & $\mathrm{TiO}_{4}$ edges \\
Si-Si & 3.50 & 3.10 & 0.22 & \\
Ti-Si & 4.0 & 3.20 & 0.25 & \\
\hline \hline
\end{tabular}

The Si-Si and Ti-Si distances were added to allow good fits for all distances less than $2.7 \AA$. The bond lengths of the possible $\mathrm{TiO}_{4}, \mathrm{TiO}_{5}$ or $\mathrm{TiO}_{6}$ units range from 1.65 to $2.10 \AA$, and thus the remaining distances of fits in this range should be due to Ti-O bonds. Their contribution is successfully approximated by a single Gaussian function at $1.81 \AA$, denoted by $\mathrm{Ti}-\mathrm{O}(1)$ in Fig. 2(b), with coordination number $\mathrm{CN}(\mathrm{Ti})$ $=4.1 \pm 0.6$ and a full width at half maximum (fwhm) of $0.12 \AA$ (Table II). Despite the uncertainty of \pm 0.6 in the Ti coordination number, a predominant tetrahedral coordination is found for $\mathrm{Ti}^{4+}$ ions in ULE glass. While the assignment of tetrahedrally coordinated $\mathrm{Ti}^{4+}$ in ULE is significant and demonstrated by X-ray diffraction, a much weaker feature at $2.17 \pm 0.05 \AA$ is also observed [Ti-O(2) in Fig. 2(b)]. This distance could be interpreted as deriving from five- or sixfold coordinated $\mathrm{Ti}^{4+}$, and has been listed as such on the basis of early EXAFS results. ${ }^{5}$ However, this feature is weak and close to the detection limit of X-ray diffraction and the distance is slightly higher compared to sixfold coordinated $\mathrm{Ti}^{4+}$ in anatase $^{3}(1.95 \AA)$ or rutile ${ }^{5}(1.96 \AA)$. Thus, our attribution of the weak feature at $2.17 \pm 0.05 \AA$ to sixfold coordinated $\mathrm{Ti}^{4+}$ is tentative. In conclusion, despite the very low concentration of $\mathrm{Ti}$ and the superposition with other atomic distances, our X-ray diffraction data show that the majority of $\mathrm{Ti}^{4+}$ ions in ULE are in fourfold coordination.

\section{Raman and infrared spectroscopy on pristine ULE}

Before presenting the vibrational spectra of laserprocessed ULE glass, we consider first the Raman and IR spectra of pristine ULE glass. The parallel- $(\mathrm{HH})$ and crosspolarized (HV) Raman spectra of ULE are shown in Fig. 3(a) in comparison to $\mathrm{v}^{-\mathrm{SiO}_{2}}$ [Fig. 3(b)]. Except for the ULEspecific Raman features at ca. 685, 937 and $1107 \mathrm{~cm}^{-1}$, which will be discussed below, the polarization behavior of the remaining ULE bands is similar to that for $\mathrm{v}-\mathrm{SiO}_{2}$. In line with the X-ray result for four-fold coordination of Si in ULE glass (Table II), we assign the silica-like Raman bands of ULE according to the broadly accepted assignments for the Raman features of ${\mathrm{v}-\mathrm{SiO}_{2}}^{21-23}$ Hence, the ULE band at ca. $400 \mathrm{~cm}^{-1}$ is attributed to the symmetric stretching-bending vibration of $\mathrm{Si}-\mathrm{O}-\mathrm{Si}$ bridges in large arrangements of $\mathrm{SiO}_{4}$ tetrahedra (5- to 8-membered rings); the weak peaks at 484 and $600 \mathrm{~cm}^{-1}$ (known as defect lines $D_{1}$ and $D_{2}$ ) to the symmetric 


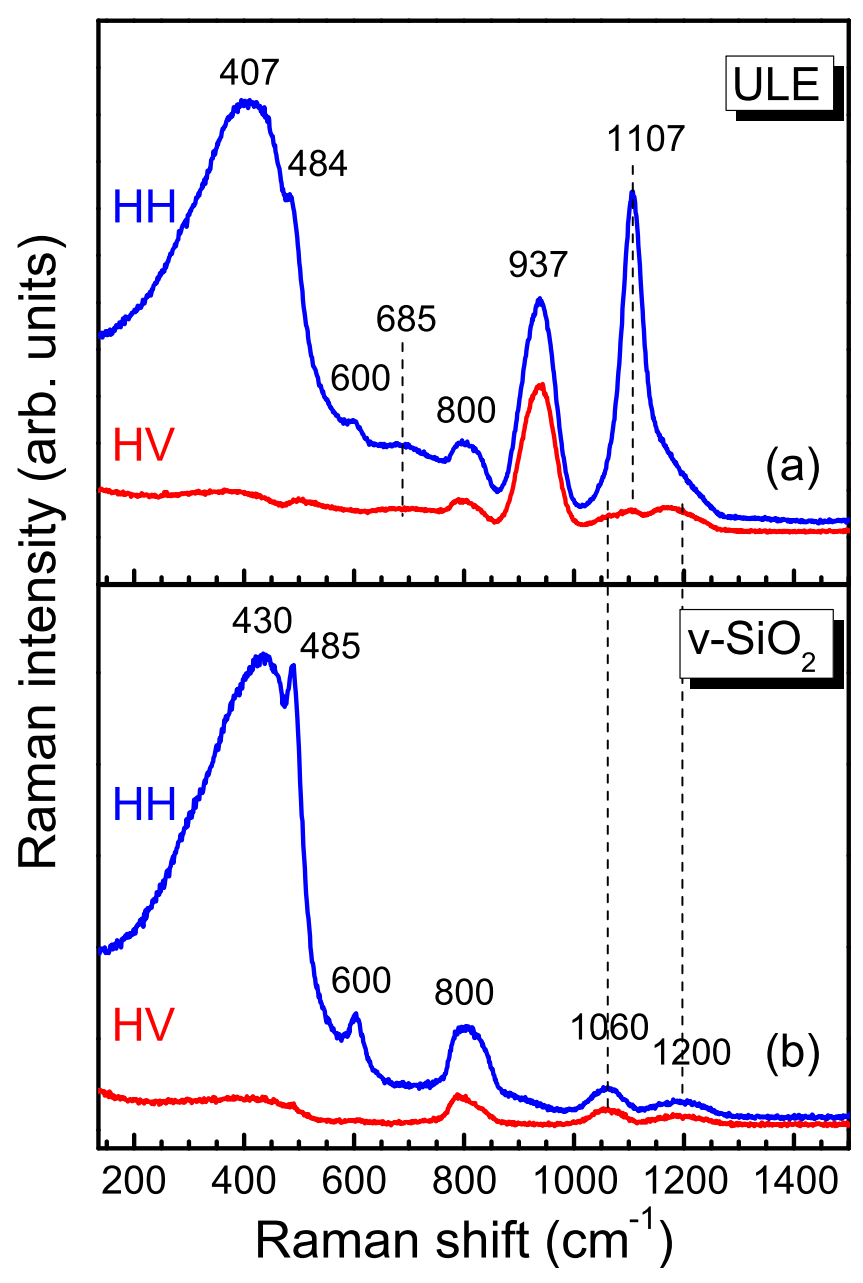

FIG. 3. Parallel (HH) and cross-polarized (HV) Raman spectra of (a) pristine ULE glass in comparison to those of vitreous silica, $\mathrm{v}-\mathrm{SiO}_{2}$ (b). Raman spectra were measured with $488 \mathrm{~nm}$ excitation.

oxygen ring breathing vibrations of 4- and 3-membered silicate rings, respectively; and the band at $800 \mathrm{~cm}^{-1}$ to Si-O-Si bending modes. As observed in Fig. 3, the main effects of $\mathrm{TiO}_{2}$ incorporation in the silicate matrix are the intensity reduction of $D_{1}$ and $D_{2}$ and the broadening and shifting of the main band from $430 \mathrm{~cm}^{-1}$ in $\mathrm{v}_{-} \mathrm{SiO}_{2}$ to $407 \mathrm{~cm}^{-1}$ in ULE. These effects suggest that the relative population of the smaller 4- and 3-membered silicate rings is reduced in ULE glass. Also, the pair of silicate bands at about 1060 and $1200 \mathrm{~cm}^{-1}$ (asymmetric stretching modes of Si-O-Si bridges) appear slightly downshifted in ULE, as seen in the HV spectrum where the influence of the $1107 \mathrm{~cm}^{-1}$ band is diminished [Fig. 3(a)].

The ULE-specific Raman features appear at 685, 937, and $1107 \mathrm{~cm}^{-1}$ [Fig. 3(a) and Table III], in agreement with earlier Raman spectra on glasses $\mathrm{xTiO}_{2}-(1-\mathrm{x}) \mathrm{SiO}_{2}{ }^{24-29} \mathrm{The}$ question now concerns the origin of these vibrational features in view of the different assignments proposed in the literature. Starting with the intense Raman peaks at 1107 and $937 \mathrm{~cm}^{-1}$, earlier assignments include the stretching of Si-O* bonds $\left(\mathrm{O}^{*}=\right.$ non-bridging oxygen $)$ in $\mathrm{Q}^{3}$ and $\mathrm{Q}^{2}$ silicate tetrahedra, ${ }^{24,29}$ where $\mathrm{Q}^{\mathrm{n}}$ is a silicate tetrahedron with 4-n nonbridging oxygen atoms; the symmetric and asymmetric stretching of $\mathrm{SiO}_{4}$ tetrahedra linked to Ti atoms; ${ }^{26}$ vibrations of Ti-rich clusters within the silicate network ${ }^{27}$ and the symmetric and asymmetric stretching vibration of $\mathrm{TiO}_{4}$ units dispersed in the $\mathrm{SiO}_{2}$ matrix. ${ }^{25}$

Association of the 1107 and $937 \mathrm{~cm}^{-1}$ bands with vibrations of silicate tetrahedra, and in particular, with the formation of non-bridging oxygen ( $\mathrm{NBO}$ ) atoms in $\mathrm{Q}^{3}$ and $\mathrm{Q}^{2}$ units should be excluded. This is because formation of NBOs, to the extent suggested by the intensity of the 1105 and $937 \mathrm{~cm}^{-1}$ bands, would modify also considerably the $200-600 \mathrm{~cm}^{-1}$ region of the Raman spectrum. ${ }^{21,30}$ As observed in Fig. 3(a), this region of the ULE spectrum resembles very much that of $\mathrm{V}-\mathrm{SiO}_{2}$. Also, the presence of NBOs usually increases the coefficient of thermal expansion, contrary to the ultra-low expansion character of the ULE glass. The monotonic increase in the 1107 and $937 \mathrm{~cm}^{-1}$ band intensity with $\mathrm{TiO}_{2}$ content in glasses $\mathrm{xTiO}_{2}-(1-\mathrm{x}) \mathrm{SiO}_{2},{ }^{27,28}$ shows that both bands should be related to internal vibrations of $\mathrm{TiO}_{4}$ units dispersed in the silicate network. ${ }^{25}$ On the basis of their polarization characteristics shown in Fig. 3(a), we assign the 937 and $1107 \mathrm{~cm}^{-1}$ bands to the asymmetric and symmetric stretching vibrations of $\mathrm{TiO}_{4}$ tetrahedra, respectively, in line with the present X-ray diffraction results. The large difference in polarizability, $\alpha$, between $\mathrm{Si}^{4+}$ and $\mathrm{Ti}^{4+}$ ions, $\alpha_{\mathrm{Si}^{4+}}=0.033 \AA^{3}$ and $\alpha_{\mathrm{Ti}^{4+}}=0.185 \AA^{3},{ }^{31}$ makes the Ti-O bond much more polarizable than $\mathrm{Si}-\mathrm{O}$, and this leads to large differences in the Raman cross section of the vibrations related to titanate and silicate units. This justifies the large relative Raman intensity of the 937 and $1107 \mathrm{~cm}^{-1}$ bands despite the fact that ULE contains less than 6 mol. $\% \mathrm{TiO}_{2}$. For convenience, the assignments of vibrational bands are collected in Table III.

In view of the present X-ray diffraction study, which does not exclude a small fraction of sixfold coordinated $\mathrm{Ti}$ ions in ULE, we assign the weak Raman feature at $\sim 685 \mathrm{~cm}^{-1}$ to the symmetric stretching vibration of $\mathrm{TiO}_{6}$ octahedral units. Raman bands at about $700 \mathrm{~cm}^{-1}$ in Tisubstituted zeolites ${ }^{32}$ and at $684 \mathrm{~cm}^{-1}$ in cobalt-doped $\mathrm{TiO}_{2}$ thin films ${ }^{33}$ were also associated with sixfold coordinated $\mathrm{Ti}^{4+}$ ions in Ti-O-Ti arrangements.

The IR reflectance spectrum of pristine ULE is displayed in Fig. 4(a) in comparison to $\mathrm{V}^{-} \mathrm{SiO}_{2}$. Besides some slight differences in intensities and frequencies, ULE shows an additional reflectance peak at $935 \mathrm{~cm}^{-1}$. This peak appears at $952 \mathrm{~cm}^{-1}$ in the absorption spectrum in Fig. 4(b), which was calculated by Kramers-Kronig transformation of the reflectance spectrum. Additional weak absorptions appear at ca. $670-770 \mathrm{~cm}^{-1}$ and $250-420 \mathrm{~cm}^{-1}$, and are in agreement with earlier spectra obtained by differential infrared spectroscopy ${ }^{34}$ and by reflectance spectroscopy. ${ }^{35}$

The ULE infrared bands at 464, 803, and $1096 \mathrm{~cm}^{-1}$ can be assigned in analogy to those of $\mathrm{v}-\mathrm{SiO}_{2} \cdot{ }^{36-38}$ The strongest IR band at $1096 \mathrm{~cm}^{-1}$, with a shoulder at $\sim 1200 \mathrm{~cm}^{-1}$, is typical of the asymmetric stretching mode of Si-O-Si bridges in a three dimensional network of $\mathrm{SiO}_{4}$ tetrahedra with four bridging oxygen atoms, and involves mainly oxygen motion along the $\mathrm{Si}-\mathrm{Si}$ direction, $v_{\mathrm{AS}}(\mathrm{Si}-\mathrm{O}-\mathrm{Si})$. The band at $803 \mathrm{~cm}^{-1}$ arises from the $\mathrm{Si}-\mathrm{O}-\mathrm{Si}$ bending mode, $v_{\mathrm{B}}(\mathrm{Si}-\mathrm{O}-$ $\mathrm{Si}$ ), with the oxygen atom moving along the bisector of the $\mathrm{Si}-\mathrm{O}-\mathrm{Si}$ bridging bond, and the one at $464 \mathrm{~cm}^{-1}$ from the 
TABLE III. Frequencies (in $\mathrm{cm}^{-1}$ ) and assignment of the main Raman and IR absorption bands of ULE glasses in comparison to vitreous silica, v-SiO ${ }_{2}$. ULE denotes the pristine ULE glass and ULEc1, ULEc2, and ULEcf the IR-probed areas of the fs laser-processed glasses of Table I. Raman peak frequencies for ULE glass are for the unpolarized spectrum $(\mathrm{HH}+\mathrm{HV})$; those for ULEc1, ULEc2, and ULEcf refer to Raman spectra measured in the molten area after laser treatment (see Fig. 7).

\begin{tabular}{|c|c|c|c|c|c|c|}
\hline Technique & Assignment & $\mathrm{v}-\mathrm{SiO}_{2}$ & ULE & ULEc1 & ULEc2 & ULEcf \\
\hline \multirow[t]{8}{*}{ Raman } & Si-O-Si symmetric stretching-bending in large silicate rings & 430 & 400 & 430 & 426 & 428 \\
\hline & 4-fold ring breathing mode & 485 & 484 & 484 & 484 & 484 \\
\hline & 3 -fold ring breathing mode & 600 & 600 & 600 & 600 & 600 \\
\hline & $\mathrm{TiO}_{6}$ symmetric stretching & $\ldots$ & 685 & 690 & 690 & 690 \\
\hline & Si-O-Si bending & 800 & 800 & 805 & 805 & 805 \\
\hline & $\mathrm{TiO}_{4}$ asymmetric stretching & $\ldots$ & 937 & 930 & 930 & 930 \\
\hline & $\mathrm{TiO}_{4}$ symmetric stretching & $\ldots$ & 1107 & 1101 & 1101 & 1101 \\
\hline & Si-O-Si asymmetric stretching & 1060,1200 & $\sim 1060, \sim 1200$ & $\sim 1060, \sim 1200$ & $\sim 1060, \sim 1200$ & $\sim 1060, \sim 1200$ \\
\hline \multirow[t]{8}{*}{ IR } & $\mathrm{Si}-\mathrm{O}-\mathrm{Si}$ rocking, $v_{\mathrm{R}}(\mathrm{Si}-\mathrm{O}-\mathrm{Si})$ & 468 & 464 & 462 & 460 & 464 \\
\hline & $\mathrm{Si}-\mathrm{O}-\mathrm{Si}$ bending, $v_{\mathrm{B}}(\mathrm{Si}-\mathrm{O}-\mathrm{Si})$ & 807 & 803 & 808 & 807 & 809 \\
\hline & $\mathrm{TiO}_{4}$ asymmetric stretching, $v_{\mathrm{as}}\left(\mathrm{TiO}_{4}\right)$ & $\ldots$ & 952 & 943 & 941 & 945 \\
\hline & $\mathrm{Si}-\mathrm{O}-\mathrm{Si}$ asymmetric stretching, $v_{\mathrm{AS}}(\mathrm{Si}-\mathrm{O}-\mathrm{Si})$ & $1099, \sim 1200$ & $1096, \sim 1200$ & $1093, \sim 1200$ & $1083, \sim 1200$ & $1100, \sim 1200$ \\
\hline & LO-TO $v_{\mathrm{AS}}(\mathrm{Si}-\mathrm{O}-\mathrm{Si})\left(\mathrm{cm}^{-1}\right)$ & 181 & 174 & 180 & 195 & 167 \\
\hline & LO-TO $v_{\mathrm{as}}\left(\mathrm{TiO}_{4}\right)\left(\mathrm{cm}^{-1}\right)$ & - & 19 & 18 & 22 & 12 \\
\hline & LO-TO $v_{\mathrm{B}}(\mathrm{Si}-\mathrm{O}-\mathrm{Si})\left(\mathrm{cm}^{-1}\right)$ & 13 & 13 & 10 & 13 & 8 \\
\hline & Si-O-Si bond angle ${ }^{\mathrm{a}}(\mathrm{deg})$ & 145.0 & 143.8 & 142.8 & 139.0 & 145.4 \\
\hline
\end{tabular}

${ }^{\mathrm{a}}$ The average value of the Si-O-Si bond angle $(\theta)$ was determined from Eq. (5) using experimental values for $v_{\mathrm{AS}}(\mathrm{Si}-\mathrm{O}-\mathrm{Si})$ and the parameters discussed in the text.

rocking motion of the bridging oxygen atom perpendicular to the $\mathrm{Si}-\mathrm{O}-\mathrm{Si}$ plane, $v_{\mathrm{R}}(\mathrm{Si}-\mathrm{O}-\mathrm{Si}$ ).

Previous assignments of the ULE-specific IR band at ca. $950 \mathrm{~cm}^{-1}$ include the stretching of non-bridging oxygen

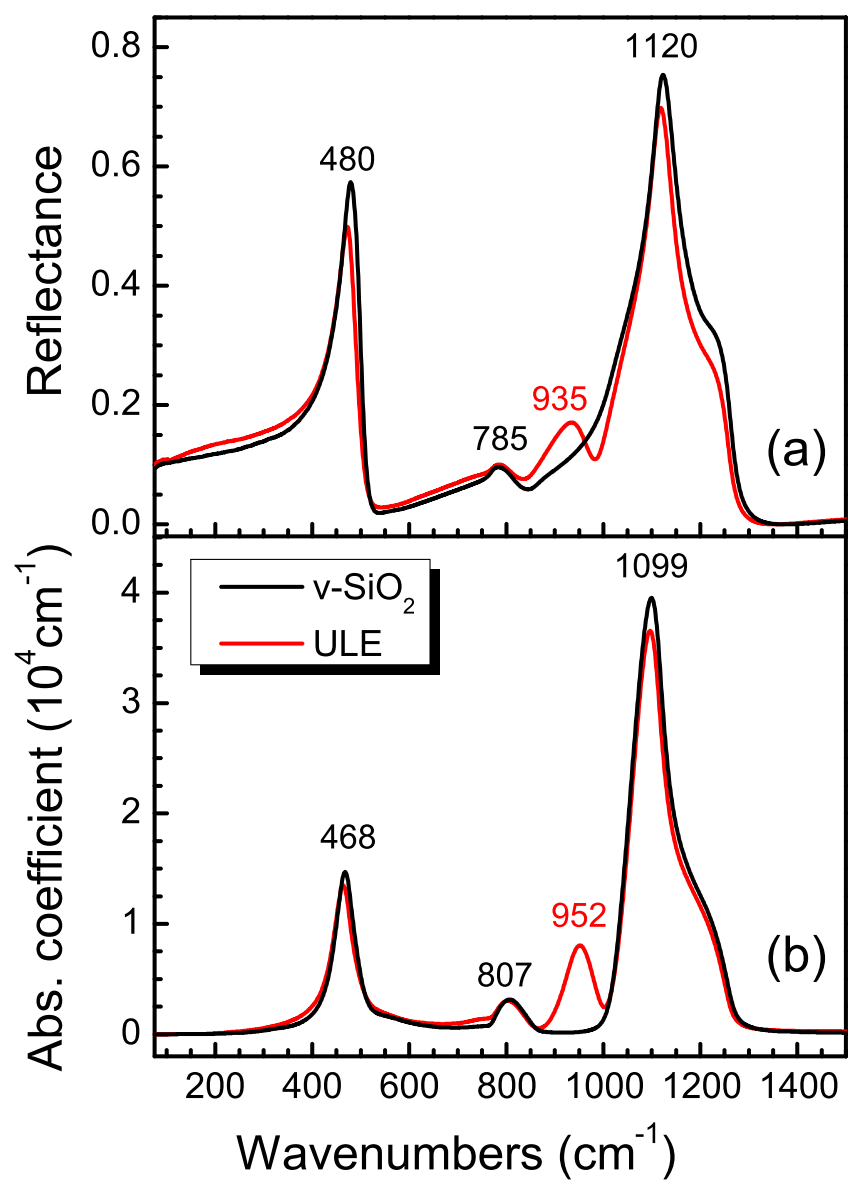

FIG. 4. Infrared spectra of pristine ULE glass (red) and $\mathrm{v}-\mathrm{SiO}_{2}$ (black) in the reflectance (a) and absorption coefficient (b) formalisms. atoms bonded to silicon, ${ }^{34}$ and the perturbation of the strong band at $1096 \mathrm{~cm}^{-1}$ involving oxygen atoms bridging the $\mathrm{SiO}_{4}$ and $\mathrm{TiO}_{4}$ tetrahedra. ${ }^{35}$ Based on the depolarized nature of the Raman band at $937 \mathrm{~cm}^{-1}$ [Fig. 3(a)], we assign the infrared band at $952 \mathrm{~cm}^{-1}$ to the asymmetric stretching of $\mathrm{TiO}_{4}$ units, $v_{\text {as }}\left(\mathrm{TiO}_{4}\right)$. The lower frequency of Ti-O stretching $\left(952 \mathrm{~cm}^{-1}\right)$ in comparison to $\mathrm{Si}-\mathrm{O}$ stretching $\left(1096 \mathrm{~cm}^{-1}\right)$ is consistent with the Ti-O bond being longer than the $\mathrm{Si}-\mathrm{O}$ bond (Table II). The very weak IR absorption at $670-770 \mathrm{~cm}^{-1}$ may arise from the asymmetric stretching of $\mathrm{TiO}_{6}$ units and Ti-O-Si bridges, whereas the $200-420 \mathrm{~cm}^{-1}$ feature could involve bending vibrations of Ti-containing structural units.

The effect of fs laser irradiation on the strongest IR band due to $v_{\mathrm{AS}}(\mathrm{Si}-\mathrm{O}-\mathrm{Si})$ will be considered in detail in $\mathrm{Sec}$. IIIC, to correlate the spectroscopic trends with microstructural changes in irradiated ULE glasses. For this approach, we employ the following simplified expressions derived for silica glass within a model including central and non-central forces: ${ }^{39}$

$$
\begin{gathered}
\nu_{A S}=\frac{1}{2 \pi c} \sqrt{\frac{2}{\mathrm{~m}_{\mathrm{O}}}\left(\mathrm{k}_{\mathrm{s}} \sin ^{2} \frac{\theta}{2}+\mathrm{k}_{\mathrm{b}} \cos ^{2} \frac{\theta}{2}\right)}, \\
\nu_{B}=\frac{1}{2 \pi c} \sqrt{\frac{4}{3 \mathrm{~m}_{\mathrm{Si}}}\left(\mathrm{k}_{\mathrm{s}}+2 \mathrm{k}_{\mathrm{b}}\right)}, \\
\nu_{R}=\frac{1}{2 \pi c} \sqrt{\frac{2 \mathrm{k}_{\mathrm{b}}}{\mathrm{m}_{\mathrm{O}}}} .
\end{gathered}
$$

Here, $\mathrm{c}$ is the speed of light, $\theta$ is the average value of the $\mathrm{Si}$ $\mathrm{O}-\mathrm{Si}$ bond angle, $\mathrm{k}_{\mathrm{s}}$ and $\mathrm{k}_{\mathrm{b}}$ are the central (bond-stretching) and non-central (bond-bending) force constants, respectively, and $\mathrm{m}_{\mathrm{O}}$ and $\mathrm{m}_{\mathrm{Si}}$ are the masses of oxygen and silicon atoms.

Since the values of $\theta, \mathrm{k}_{\mathrm{s}}$, and $\mathrm{k}_{\mathrm{b}}$ are not known for ULE, we employ as input relevant data derived for silica glass. Using the measured value for the Si-O-Si rocking frequency, 
$v_{\mathrm{R}}(\mathrm{Si}-\mathrm{O}-\mathrm{Si})=468 \mathrm{~cm}^{-1}$, we obtain from Eq. (4) the value $\mathrm{k}_{\mathrm{b}}=103.2 \mathrm{~N} / \mathrm{m}$ for the non-central force constant. The value of the central force constant is then derived from Eq. (2) using $\mathrm{k}_{\mathrm{b}}=103.2 \mathrm{~N} / \mathrm{m}$, the experimental value for the Si-O-Si asymmetric stretching $v_{\mathrm{AS}}(\mathrm{Si}-\mathrm{O}-\mathrm{Si})=1099 \mathrm{~cm}^{-1}$ and an average bond angle of $\theta=145^{\circ}$, according to X-ray diffraction $^{40}$ and nuclear magnetic resonance ${ }^{41,42}$ studies on silica glass. This approach results in $\mathrm{k}_{\mathrm{s}}=615.7 \mathrm{~N} / \mathrm{m}$. To check the validity of the derived force constants, we employ Eq. (3) to calculate the frequency of the $\mathrm{Si}-\mathrm{O}-\mathrm{Si}$ bending mode. The result $v_{\mathrm{B}}=814 \mathrm{~cm}^{-1}$ is in good agreement with the experimental value $\left(807 \mathrm{~cm}^{-1}\right.$, with less than $1 \%$ difference), considering the asymmetric lineshape of this mode.

Figure 5 shows $v_{\mathrm{AS}}(\mathrm{Si}-\mathrm{O}-\mathrm{Si})$ versus $\theta$ according to Eq. (2); the results demonstrate a monotonic increase in $v_{\mathrm{AS}}(\mathrm{Si}-$ $\mathrm{O}-\mathrm{Si}$ ) with the $\mathrm{Si}-\mathrm{O}-\mathrm{Si}$ bond angle. In Fig. 5 are also marked the measured $v_{\mathrm{AS}}(\mathrm{Si}-\mathrm{O}-\mathrm{Si})$ frequencies for pristine ULE and for the IR-probed areas of the laser-processed glasses ULEc1, ULEc2, and ULEcf (the latter will be discussed in Sec. III C). The result for the average Si-O-Si bond angle in pristine ULE glass is $\theta=143.8^{\circ}$, and this corresponds to a shift by $-1.2^{\circ}$ relative to silica glass $\left(\theta=145^{\circ}\right) .^{40,41}$

\section{Resonance Raman enhancement in pristine ULE glass}

Comparison of the spectrum of ULE glass in Fig. 3(a) with reported Raman spectra ${ }^{27,29}$ of glasses $x \mathrm{TiO}_{2}-(1-\mathrm{x}) \mathrm{SiO}_{2}$ shows that the relative intensity of the $\mathrm{TiO}_{4}$ bands at 1107 and $937 \mathrm{~cm}^{-1}$ varies with excitation wavelength. To explore this effect in ULE, we have measured Raman spectra with laser excitation spanning the range from near-infrared $(1064 \mathrm{~nm})$ to visible $(633,514$, and $488 \mathrm{~nm})$ and to UV

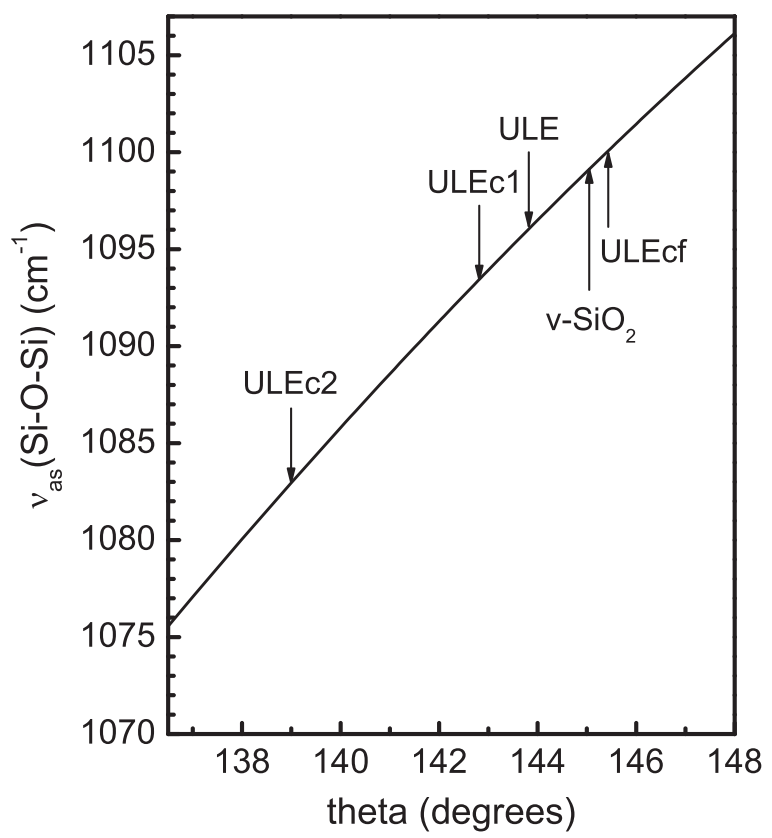

FIG. 5. The infrared peak frequency of the Si-O-Si asymmetric stretching mode, $v_{\mathrm{AS}}(\mathrm{Si}-\mathrm{O}-\mathrm{Si})$, as a function of the inter-tetrahedral $\mathrm{Si}-\mathrm{O}-\mathrm{Si}$ bond angle, $\theta$, according to Eq. (2). The arrows mark the measured peak positions for vitreous silica, pristine ULE glass, and fs-laser proccesed samples ULEc1, ULEc2, and ULEcf.
$(325 \mathrm{~nm})$. The spectra in Fig. 6 show that the $1107 \mathrm{~cm}^{-1}$ $\mathrm{TiO}_{4}$ band gains intensity relative to the $937 \mathrm{~cm}^{-1}$ band and relative to the $\mathrm{SiO}_{2}$-type bands at 400, 484, 600, and $800 \mathrm{~cm}^{-1}$. The enhancement of the $1107 \mathrm{~cm}^{-1}$ band follows the wavelength dependence of the ULE absorption coefficient, which shows an absorption edge at about $315 \mathrm{~nm}$ (Fig. 7). To quantify this effect, we plot in the inset of Fig. 7 the ratio of intensities at 1107 and $937 \mathrm{~cm}^{-1}, \mathrm{I}_{1107} / \mathrm{I}_{937}$, as a function of excitation wavelength; clearly, the totally symmetric $\mathrm{TiO}_{4}$ mode shows selective enhancement upon decreasing excitation wavelength.

Ti-doped silica glass gives a very strong absorption at about $200 \mathrm{~nm}(6.2 \mathrm{eV})$, the recording of which requires reflectance measurements in this spectral range ${ }^{35}$ or transmission measurements on very thin films. ${ }^{43,44}$ Absorption at $200 \mathrm{~nm}$ is attributed to a charge-transfer (CT) transition localized primarily at $\mathrm{TiO}_{4}$ tetrahedra, and involving an electron transfer from the oxygen ligands to the central titanium ion to fill up the vacant $\mathrm{d}^{0}$ orbital of $\mathrm{Ti}^{4+}$ ion, i.e., $\mathrm{O}^{2-}\left(2 \mathrm{~s}^{2}\right.$ $\left.3 \mathrm{p}^{6}\right) \rightarrow \mathrm{Ti}^{4+}\left(3 \mathrm{~d}^{0}\right)$. This ligand-to-metal $(\mathrm{L} \rightarrow \mathrm{M})$ CT creates a $\mathrm{Ti}^{3+}$ ion $\left(3 \mathrm{~d}^{1}\right)$ and leaves a hole shared by the tetrahedral cage of oxygen ions, i.e., a localized exciton. $35,43,44$

Based on the presence of the $\mathrm{O}^{2-} \rightarrow \mathrm{Ti}^{4+} \mathrm{CT}$ band at about $200 \mathrm{~nm}$, Fig. 7 shows that excitation of the Raman spectrum with UV light $(325 \mathrm{~nm})$ gets into resonance with

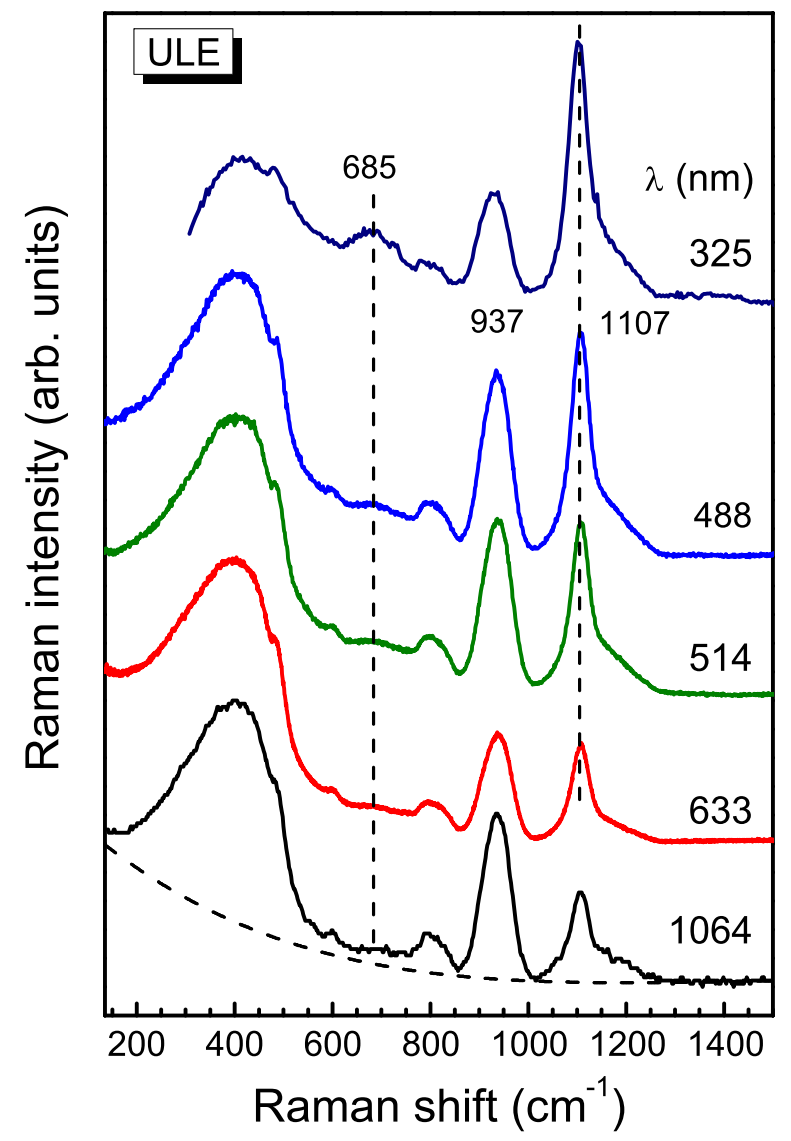

FIG. 6. Unpolarized Raman spectra of the pristine ULE glass measured with laser excitation wavelengths covering the range from near-infrared $(1064 \mathrm{~nm})$ to UV $(325 \mathrm{~nm})$. Note that the curved dashed line drawn for the $1064 \mathrm{~nm}$ spectrum represents a fourth-order polynomial background and the filter employed to measure the Raman spectrum with $325 \mathrm{~nm}$ excitation has a cutoff at $300 \mathrm{~cm}^{-1}$. 


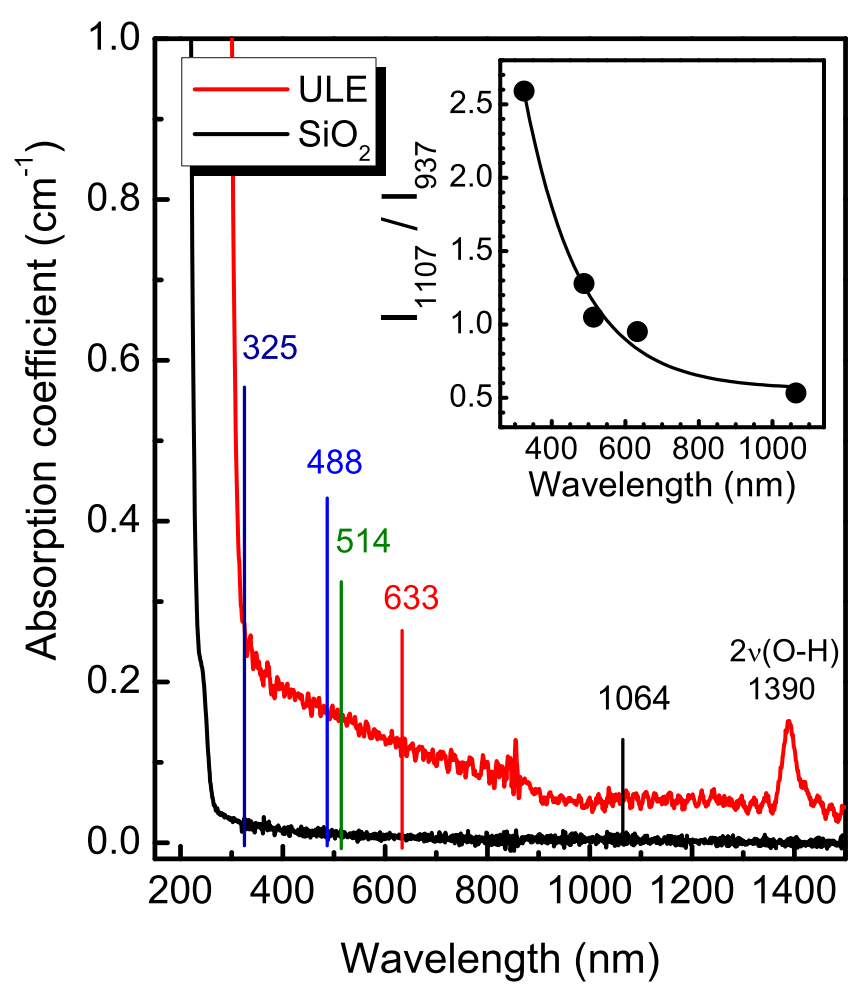

FIG. 7. Absorption coefficient spectra in the UV-VIS-NIR region for pristine ULE glass (red) in comparison to vitreous $\mathrm{SiO}_{2}$ (black). The values of the absorption coefficient were derived from the as-measured transmittance spectra using Eq. (1). The inset shows the ratio of intensities for the symmetric, $1107 \mathrm{~cm}^{-1}$, and asymmetric, $937 \mathrm{~cm}^{-1}$, stretching modes of $\mathrm{TiO}_{4}$ tetrahedra measured from the Raman spectra of ULE glass as a function of excitation wavelength. To obtain the Raman peak intensities, a fourth-order polynomial background was subtracted for all Raman spectra as shown in Fig. 6 for the $1064 \mathrm{~nm}$ spectrum. The line in the inset is a guide to the eye.

the CT band localized at $\mathrm{TiO}_{4}$ tetrahedra. This leads to resonance Raman enhancement of the totally symmetric mode with respect to the absorbing titanium center as observed for the $1107 \mathrm{~cm}^{-1}$ band (Fig. 6 and inset of Fig. 7), in agreement with previous studies on titanium-silicate catalysts. ${ }^{45,46}$ With reference to UV excitation in Fig. 7, the 633, 514, and $488 \mathrm{~nm}$ lines lead progressively to pre-resonance Raman enhancement as these lines are in the tail of the strong $\mathrm{O}^{2-}$ $\rightarrow \mathrm{Ti}^{4+} \mathrm{CT}$ band.

Inspection of Fig. 6 also reveals a gradual enhancement of the feature at about $685 \mathrm{~cm}^{-1}$ as laser excitation approaches the UV region. In analogy to $\mathrm{TiO}_{4}$ tetrahedra, we propose that this effect is consistent with resonance Raman enhancement of the symmetric stretching vibration of $\mathrm{TiO}_{6}$ octahedral units in ULE glass. This is supported by the presence of an $\mathrm{O}^{2-} \rightarrow \mathrm{Ti}^{4+} \mathrm{CT}$ band localized at $\mathrm{TiO}_{6}$ octahedra, which is in the same spectral region with the CT band of $\mathrm{TiO}_{4}$ tetrahedral units. ${ }^{47}$

\section{B. Raman spectroscopy of laser-processed ULE glass}

Having considered the Raman and infrared response of pristine ULE, we focus now on the spectral changes induced by laser irradiation as probed by micro-Raman and IR reflectance spectroscopy (Sec. III C).

Raman spectra of laser-processed ULE glasses are shown in Fig. 8; they were measured at spots located in the

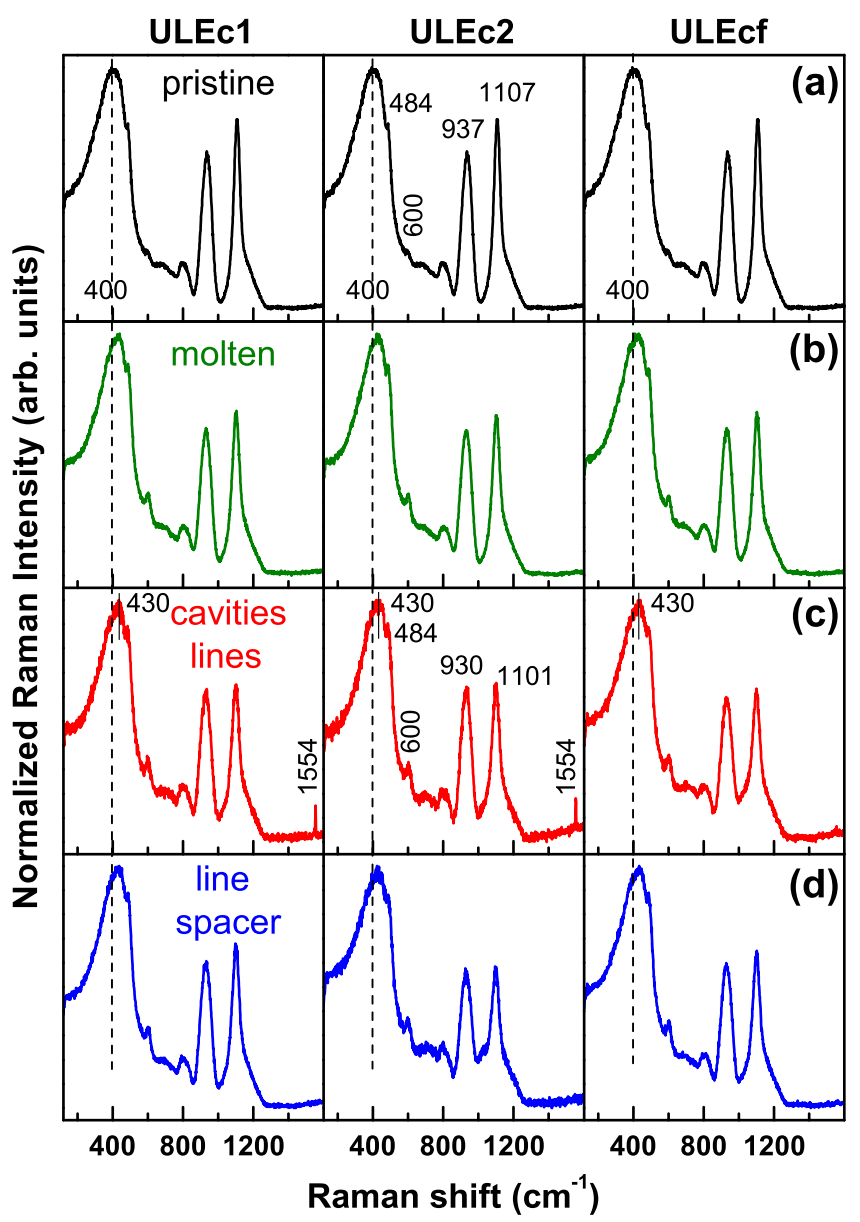

FIG. 8. Unpolarized (HH+HV) Raman spectra of fs laser-processed ULE glasses in comparison to pristine ULE glass [black (a)], measured with $488 \mathrm{~nm}$ excitation. To facilitate comparison, all spectra were normalized with respect to the ca. $400 \mathrm{~cm}^{-1}$ band and treated to have the same baseline above $1300 \mathrm{~cm}^{-1}$. The spectra of laser-processed glasses were measured at spots in the molten zones [green (b)], cavities/lines written by the laser [red (c)], and in between laser-written lines [blue (d)]. For visualization of the various zones, see Fig. 1.

pristine, molten, cavities/lines, and in between cavities/lines regions ("line spacer") as indicated in Fig. 1. To facilitate spectral comparison, all Raman spectra were normalized on the band at $400-430 \mathrm{~cm}^{-1}$ and were treated to have the same baseline above $1300 \mathrm{~cm}^{-1}$. According to Fig. 8, the effect of laser treatment on ULE glass can be summarized as follows:

(a) The main silica-type band shifts from about 400 to $430 \mathrm{~cm}^{-1}$.

(b) The $600 \mathrm{~cm}^{-1}$ peak $\left(\mathrm{D}_{2}\right)$ is enhanced by laser radiation.

(c) The $\mathrm{TiO}_{4}$-related peaks, at 937 and $1107 \mathrm{~cm}^{-1}$ in pristine ULE, both exhibit lower relative intensity and frequency reduction upon laser irradiation.

(d) A new sharp band is observed at $1554 \mathrm{~cm}^{-1}$ for spectra measured at cavities of ULEc1 and ULEc2, and can be attributed to the stretching vibration of molecular oxygen. $^{48,49}$

The response of the $400-430 \mathrm{~cm}^{-1}$ band and that of the $\mathrm{D}_{2}$ peak point to silicate structural rearrangements is caused by laser irradiation. We note that enhancement of the $\mathrm{D}_{1}$ and $D_{2}$ peaks has been reported for pure silica glass after intense 
laser irradiation, ${ }^{50-53}$ and permanent densification induced by pressure, ${ }^{54-56}$ shock waves ${ }^{57}$ or indentation. ${ }^{58}$ In any case, the enhancement of $D_{2}$ shown in Fig. 8 is weak compared to that observed in previous studies of permanently densified silica glass. ${ }^{50-58}$ The present Raman results show that laser fs irradiation of ULE glass leads to rearrangements in the silicate network, the reduction in the population of $\mathrm{TiO}_{4}$ tetrahedral units with tetravalent titanium $\left(\mathrm{Ti}^{4+}\right)$ and to the parallel formation and trapping of $\mathrm{O}_{2}$ in cavities.

To quantify such laser-induced microstructural transformations, we have created Raman maps in $2 \mu \mathrm{m}$ steps over $80 \mu \mathrm{m} \times 30 \mu \mathrm{m}$ laser-modified areas in ULEc1, ULEc2, and ULEcf. Each Raman spectrum was normalized and baselinecorrected as described above. The relative integrated peak intensities for selected Raman bands are shown in Fig. 9 in comparison to pristine ULE. It is clear that the $600 \mathrm{~cm}^{-1}$ peak $\left(\mathrm{D}_{2}\right)$ gains intensity in the laser-treated areas of all ULE samples, being relatively more intense along cavities/lines written by the laser beam [Fig. 9(a)]. Therefore, laser treatment increases the relative population of 3-membered silicate rings in ULE glass. Mapping of the band at $1550 \mathrm{~cm}^{-1}$ [Fig. 9(b)] shows that $\mathrm{O}_{2}$ is present only in the cavities of ULEc1 and ULEc2, and the band is more intense for the densely written ULEc2 sample.

As noted above, both bands at 937 and $1107 \mathrm{~cm}^{-1}$ for pristine ULE lose intensity upon laser irradiation. However, inspection of Fig. 8 shows that the intensity reduction of the symmetric stretching mode of $\mathrm{TiO}_{4}$ tetrahedral units $\left(1107 \mathrm{~cm}^{-1}\right)$ is more effective than that of the asymmetric mode at $937 \mathrm{~cm}^{-1}$. This is manifested clearly in the maps of Fig. 9(c) presenting the relative integrated intensity $I_{1107} / I_{937}$. The integrated intensity of the $1107 \mathrm{~cm}^{-1}$ band was obtained by deconvoluting the $1000-1300 \mathrm{~cm}^{-1}$ envelope into three Gaussian components at ca. $1104 \mathrm{~cm}^{-1}, v_{\mathrm{s}}\left(\mathrm{TiO}_{4}\right)$, and at ca. 1035-1075 and $1140 \mathrm{~cm}^{-1}$ (Si-O-Si asymmetric stretching, see also the HV spectrum of ULE in Fig. 3(a) where these bands are better distinguishable). At the same time, the features of the ca. $937 \mathrm{~cm}^{-1}$ band (i.e., frequency, bandwidth, intensity) were obtained by fitting the $850-1000 \mathrm{~cm}^{-1}$ envelope with one Gaussian component. The maps in Fig. 9(c) show that the reduction in the relative intensity of the $1107 \mathrm{~cm}^{-1}$ band is more drastic along the laser-written cavities/lines than the surrounding molten and re-solidified material. It is of interest to note that ULEcf exhibits a similar trend of $I_{1107} / I_{937}$ even though there are no cavities in the probed glass areas.

To understand the origin of this effect, we note that UVVis spectroscopy on laser-modified ULE glasses showed the development of a relatively sharp peak at $300 \mathrm{~nm}$ and a weak broad absorption peak at $790 \mathrm{~nm}$, attributed tentatively to defects generated at high pulse energies and to the ${ }^{2} \mathrm{E}_{\mathrm{g}}\left({ }^{2} \mathrm{D}\right)$ $\rightarrow{ }^{2} \mathrm{~T}_{2 \mathrm{~g}}\left({ }^{2} \mathrm{D}\right) \mathrm{d}$-d transition of tetrahedral $\mathrm{Ti}^{3+}$, respectively. ${ }^{12}$ In addition, it was found that absorption below $300 \mathrm{~nm}$ is drastically reduced upon laser irradiation, and this signals the reduction in intensity of the $\mathrm{O}^{2-} \rightarrow \mathrm{Ti}^{4+} \mathrm{CT}$ transition because of the photo-reduction of $\mathrm{Ti}^{4+}$ to $\mathrm{Ti}^{3+}$. Under such conditions, Raman excitation at $488 \mathrm{~nm}$ moves further away from the CT band and thus pre-resonance enhancement of the symmetric stretching mode at $1107 \mathrm{~cm}^{-1}$ is nearly lost.
In summary, laser irradiation reduces the population of $\mathrm{TiO}_{4}$ tetrahedral units with $\mathrm{Ti}^{4+}$ and, thus, reduces the intensity of the bands at 937 and $1107 \mathrm{~cm}^{-1}$ bands. At the same time, pre-resonance Raman conditions are not satisfied anymore with $488 \mathrm{~nm}$ excitation and this reduces additionally the intensity of the symmetric stretching band at $1107 \mathrm{~cm}^{-1}$.

In addition to changes in intensity, laser irradiation was found to affect also the frequency of the symmetric and asymmetric stretching modes of the $\mathrm{TiO}_{4}$ tetrahedral units as shown in the maps of Figs. 9(d) and 9(e), respectively. Interestingly, the apparent frequency of both modes is reduced in the lasertreated areas in a rather periodic but quite complementary way; the frequency of the symmetric stretching is reduced to a larger extent along laser-written cavities/lines whereas the asymmetric mode shows a larger frequency reduction in the surrounding molten and re-solidified material.

Such frequency variations reflect changes in the local chemistry/bonding characteristics of the $\mathrm{TiO}_{4}$ tetrahedra. To explore the origin of such changes, we obtained the bandwidths of the $v_{\mathrm{s}}\left(\mathrm{TiO}_{4}\right)$ and $v_{\mathrm{as}}\left(\mathrm{TiO}_{4}\right)$ modes as described above and present them in the maps of Figs. 9(f) and 9(g), respectively. Laser irradiation is found to increase both bandwidths $\left[\Delta v_{\mathrm{s}}\left(\mathrm{TiO}_{4}\right)\right.$ and $\left.\Delta v_{\mathrm{as}}\left(\mathrm{TiO}_{4}\right)\right]$, suggesting a broader distribution of $\mathrm{TiO}_{4}$ sites in all laser-treated ULE glasses. Previous studies have shown that in several series of tetrahedral oxoanions, the frequencies of both symmetric and asymmetric stretching modes decrease as the oxidation state of the metal is lowered. ${ }^{59}$ On this basis, the apparent frequency reduction and the increased bandwidth of both $v_{\mathrm{s}}\left(\mathrm{TiO}_{4}\right)$ and $v_{\text {as }}\left(\mathrm{TiO}_{4}\right)$ modes should reflect the formation of $\mathrm{TiO}_{4}$ tetrahedral sites of $\mathrm{Ti}^{3+}$, in addition to the remaining $\mathrm{TiO}_{4}$ tetrahedral sites of $\mathrm{Ti}^{4+}$ ions. The decrease in the titanium oxidation state from $4+$ to $3+$ is probably not large enough to produce $v_{\mathrm{s}}\left(\mathrm{Ti}^{3+} \mathrm{O}_{4}\right)$ and $v_{\text {as }}\left(\mathrm{Ti}^{3+} \mathrm{O}_{4}\right)$ peaks for the $\mathrm{Ti}^{3+}$ tetrahedral sites which are well-resolved from $v_{\mathrm{s}}\left(\mathrm{Ti}^{4+} \mathrm{O}_{4}\right)$ $=1107 \mathrm{~cm}^{-1}$ and $v_{\text {as }}\left(\mathrm{Ti}^{4+} \mathrm{O}_{4}\right)=937 \mathrm{~cm}^{-1}$ peaks for $\mathrm{Ti}^{4+}$ tetrahedral sites, respectively. To verify this hypothesis, we use $v_{\mathrm{s}}$ and $v_{\text {as }}$ frequency data for $\mathrm{M}^{\mathrm{n}+} \mathrm{O}_{4}$ and $\mathrm{M}^{(\mathrm{n}-1)+} \mathrm{O}_{4}$ tetrahedral sites for $\mathrm{M}=\mathrm{V}^{5+} / \mathrm{V}^{4+}, \mathrm{Cr}^{7+} / \mathrm{Cr}^{6+}, \mathrm{Cr}^{6+} / \mathrm{Cr}^{5+}, \mathrm{Cr}^{5+} / \mathrm{Cr}^{4+}$, $\mathrm{Mn}^{7+} / \mathrm{Mn}^{6+}$, and $\mathrm{Mn}^{6+} / \mathrm{Mn}^{5+}{ }^{59} \mathrm{It}$ is found that, on the average, $\quad v_{\mathrm{s}}\left(\mathrm{M}^{(\mathrm{n}-1)+} \mathrm{O}_{4}\right)=0.98 v_{\mathrm{s}}\left(\mathrm{M}^{\mathrm{n}+} \mathrm{O}_{4}\right)$ and $v_{\mathrm{as}}\left(\mathrm{M}^{(\mathrm{n}-1)+} \mathrm{O}_{4}\right)$ $=0.97 v_{\text {as }}\left(\mathrm{M}^{\mathrm{n}+} \mathrm{O}_{4}\right)$. If this is the case for the $\mathrm{Ti}^{4+} / \mathrm{Ti}^{3+}$ sites considered here, we expect $v_{\mathrm{s}}\left(\mathrm{Ti}^{3+} \mathrm{O}_{4}\right)$ at $1087 \mathrm{~cm}^{-1}$ and $v_{\text {as }}\left(\mathrm{Ti}^{3+} \mathrm{O}_{4}\right)$ at $908 \mathrm{~cm}^{-1}$. Thus, the laser-induced frequency shifts compared to pristine ULE glass would be $\Delta v_{\mathrm{s}}$ $=-20 \mathrm{~cm}^{-1}$ and $\Delta v_{\mathrm{as}}=-29 \mathrm{~cm}^{-1}$. However, these shifts are comparable or smaller than the half width at half maximum of the corresponding Raman bands in Fig. 3(a), which are about $20 \mathrm{~cm}^{-1}$ and $35 \mathrm{~cm}^{-1}$ for the $1107 \mathrm{~cm}^{-1}$ and $937 \mathrm{~cm}^{-1}$ bands, respectively. Therefore, we may conclude that laser irradiation of ULE glass does not create distinct Raman peaks for the $v_{\mathrm{s}}\left(\mathrm{Ti}^{3+} \mathrm{O}_{4}\right)$ and $v_{\mathrm{as}}\left(\mathrm{Ti}^{3+} \mathrm{O}_{4}\right)$; instead, it causes the apparent downshift and broadening of the 1107 and $937 \mathrm{~cm}^{-1}$ bands.

Summarizing this section, micro-Raman spectroscopy showed that restructuring of the silicate network, e.g., enhancement of $\mathrm{D}_{2}$, is accompanied by the reduction of $\mathrm{Ti}^{4+}$ to $\mathrm{Ti}^{3+}$ and the formation of molecular oxygen trapped in cavities. In our previous report, ${ }^{12}$ we considered the 


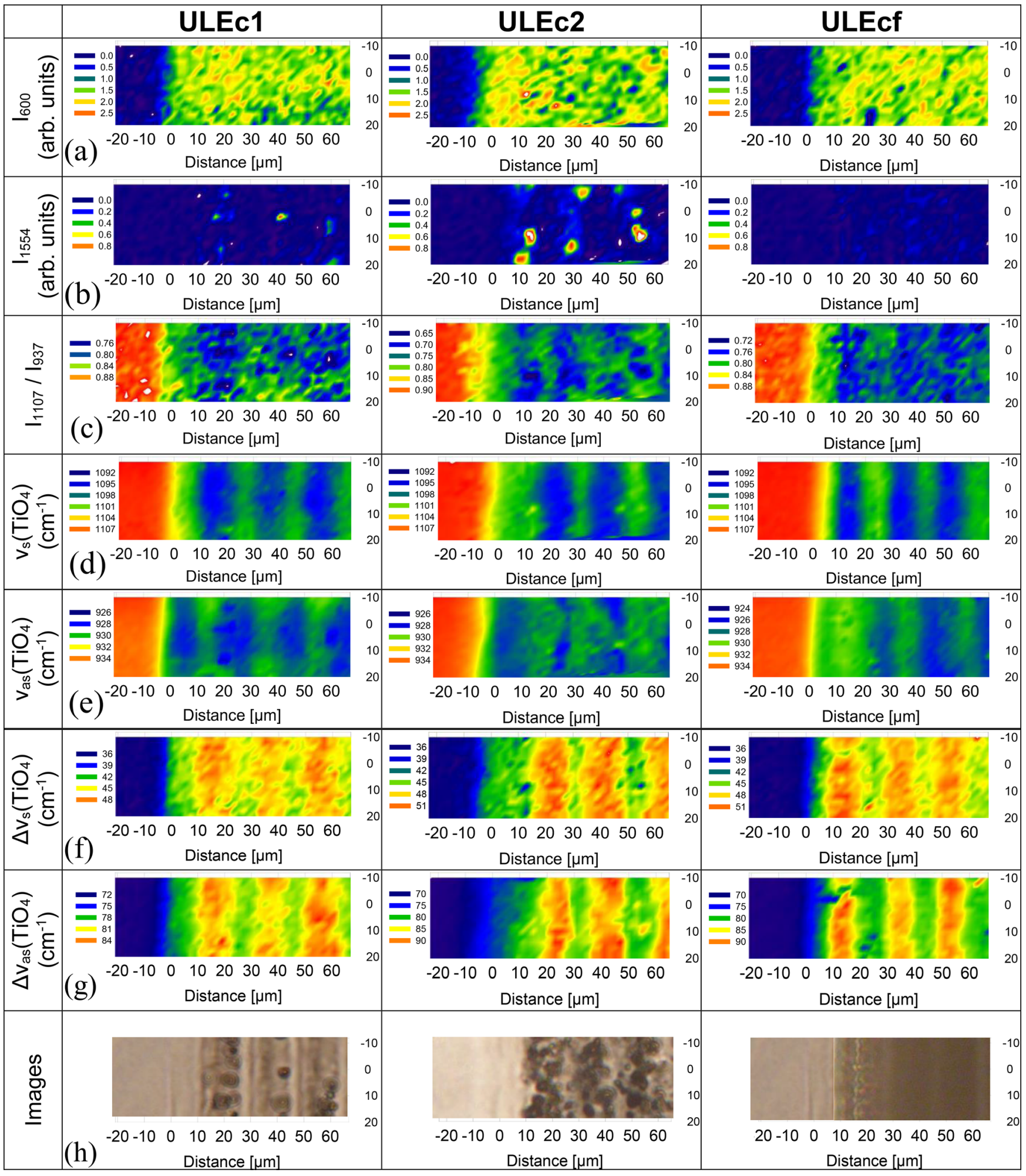

FIG. 9. Maps of characteristic peaks of the normalized Raman spectra of laser-processed ULE glasses measured with the $488 \mathrm{~nm}$ excitation. (a) Integrated intensity of the $600 \mathrm{~cm}^{-1}$ peak due to 3-membered silicate rings. (b) Integrated intensity of the $1554 \mathrm{~cm}^{-1}$ peak due to molecular oxygen. (c) Relative integrated intensity $\mathrm{I}_{1107} / \mathrm{I}_{937}$ of the peaks due to symmetric and asymmetric stretching of $\mathrm{TiO}_{4}$ tetrahedral units. Maps (d) and (e) present frequency and maps (f) and $(\mathrm{g})$ bandwidth of the symmetric and asymmetric stretching vibrations of $\mathrm{TiO}_{4}$ tetrahedral units, respectively. The Raman maps correspond to the areas of samples ULEc1, ULEc2, and ULEcf shown in the images in the lower row of (h).

increased population of three-member rings (band $\left.\mathrm{D}_{2}\right)$ as evidence for densification of the silicate network. However, a study on the binary silicate glass $25 \mathrm{GeO}_{2}-75 \mathrm{SiO}_{2}$ demonstrated that the Raman bands $\mathrm{D}_{1}$ and $\mathrm{D}_{2}$ cannot be used as reliable signatures of densification. ${ }^{60}$ Indeed, while the $\mathrm{D}_{1}$ and $\mathrm{D}_{2}$ intensity increased with increasing fictive temperature, the glass density was found to decrease for $25 \mathrm{GeO}_{2}$ $75 \mathrm{SiO}_{2}$. Considering that ULE is also a binary silicate glass, $5.67 \mathrm{TiO}_{2}-94.33 \mathrm{SiO}_{2}$, we employ in Sec. IIIC the strongest IR $v_{\mathrm{AS}}(\mathrm{Si}-\mathrm{O}-\mathrm{Si})$ mode as an alternative spectroscopic tool to 
probe possible local density variations in ULE due to laser irradiation.

\section{Infrared spectroscopy of laser-processed ULE glass}

\section{General considerations}

In comparison to micro-Raman spectroscopy with spatial resolution better than $1 \mu \mathrm{m}$, IR reflectance spectroscopy gives an average response over practically an entire laserwritten area since spectra were collected with a $3 \mathrm{~mm}$ aperture. With reference to pristine ULE, the level of the measured infrared reflectance after laser treatment shows a clear dependence on the type of regions exposed to and, thus, probed by the infrared radiation (Fig. 10); ULEc2 shows the highest reflectivity, ULEc1 and ULE follow and ULEcf exhibits the lowest reflectivity. For example, focusing on the reflectance of the strongest peak at ca. $1120 \mathrm{~cm}^{-1}$, we note that its value decreases from $90 \%$ (ULEc2) to $72 \%$ (ULEc1) and to $69 \%$ (ULE) and reaches its lowest value of $53 \%$ for ULEcf. Also, the far-IR response shows a sample/ exposed region dependence; for example, the reflectance at $200 \mathrm{~cm}^{-1}$ increases from about $13 \%$ (ULE) to $19 \%$ (ULEc1) and to $26 \%$ (ULEc2) and remains practically the same (13\%) for ULEcf.

The increased far-IR reflectance suggests the development of semiconducting character after intense laser irradiation and hints the formation of $\mathrm{Ti}_{2} \mathrm{O}_{3}$ where titanium is

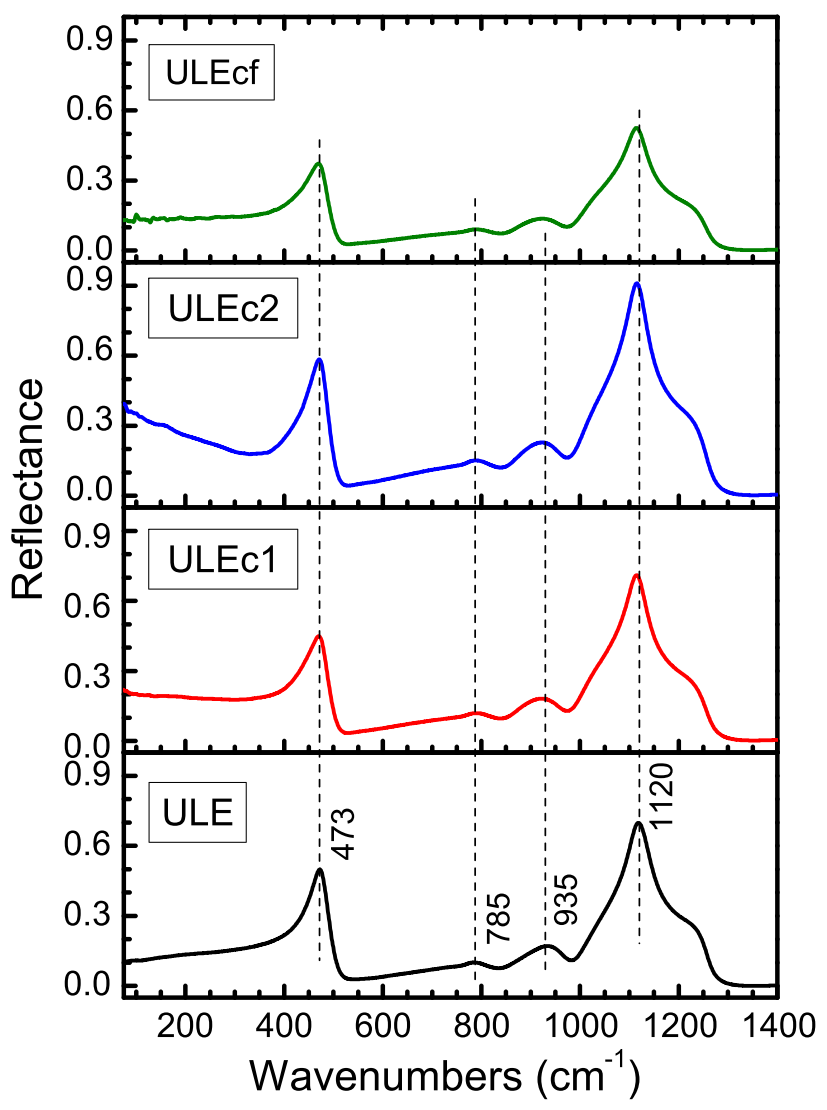

FIG. 10. Near-normal incidence infrared reflectance spectra measured on pristine (ULE) and those exposed to spectroscopy areas of the laserprocessed glasses (ULEc1, ULEc2, and ULEcf). present in the $\mathrm{Ti}^{3+}$ oxidation state. ${ }^{61}$ Besides its high far-IR reflectance, crystalline $\mathrm{Ti}_{2} \mathrm{O}_{3}$ shows relatively sharp features below $550 \mathrm{~cm}^{-1}$ which are due to the IR-active phonons measured at 280,376, 451, and $511 \mathrm{~cm}^{-1}$ when the electric field of the infrared radiation $(\mathrm{E})$ is polarized perpendicular to the $c$-axis, and at 343 and $448 \mathrm{~cm}^{-1}$ for $E$ polarized parallel to the $c$-axis. ${ }^{61}$ The absence of sharp far-IR features in the spectrum of ULEc2 suggests instead the formation of disordered $\mathrm{Ti}_{2} \mathrm{O}_{3}$ clusters by laser irradiation, noting that disordered $\mathrm{Ti}_{2} \mathrm{O}_{3}$ is also a narrow band-gap semiconductor ${ }^{62}$ similar to its crystalline counterpart. A semiconducting character of the laser-treated ULEc2 surface explains its increased overall reflectivity when compared to pristine ULE as we discussed above. These findings are in agreement with the presence of a larger number of cavities, i.e., more $\mathrm{Ti}_{2} \mathrm{O}_{3}$ containing areas in ULEc2 (see also Fig. 1). On the other hand, the IR-probed area in ULEcf lies below such cavities as shown in Fig. 1, and this is consistent with its low far-IR reflectance. The probed areas in ULEc1 are intermediate to those in ULEc2 and ULEcf in terms of imaging (Fig. 1) and their IR reflectance response (Fig. 10).

\section{Laser-induced structural rearrangements and local density variations in ULE glass}

Differences in the IR reflectance spectra between fs laser-processed glasses and pristine ULE are reflected in the corresponding absorption spectra, and concern mainly shifts of the titanate band at $952 \mathrm{~cm}^{-1}, v_{\mathrm{as}}\left(\mathrm{TiO}_{4}\right)$, and the silicate network bands at $1096 \mathrm{~cm}^{-1}, v_{\mathrm{AS}}(\mathrm{Si}-\mathrm{O}-\mathrm{Si}), 803 \mathrm{~cm}^{-1}, v_{\mathrm{B}}(\mathrm{Si}-$ $\mathrm{O}-\mathrm{Si}$ ), and $464 \mathrm{~cm}^{-1}, v_{\mathrm{R}}(\mathrm{Si}-\mathrm{O}-\mathrm{Si}$ ) (Fig. 11 and Table III). It is found that $v_{\text {as }}\left(\mathrm{TiO}_{4}\right)$ downshifts for all laser-processed ULE glasses, in agreement with the Raman results (Figs. 8 and 9), while $v_{\mathrm{B}}(\mathrm{Si}-\mathrm{O}-\mathrm{Si})$ shows the opposite trend and $v_{\mathrm{R}}(\mathrm{Si}-\mathrm{O}-\mathrm{Si})$ downshifts for ULEc1 and ULEc2 and remains unchanged for ULEcf. The behavior of the strongest $v_{\mathrm{AS}}(\mathrm{Si}-$ $\mathrm{O}-\mathrm{Si}$ ) mode is of main interest; it downshifts for ULEc1 and ULEc2, but for ULEcf it appears at higher frequency compared to ULE (1100 vs $1096 \mathrm{~cm}^{-1}$ ). Redshifts of $v_{\mathrm{AS}}(\mathrm{Si}-\mathrm{O}-$ $\mathrm{Si}$ ) have been observed in silica glasses densified at high pressures/temperatures, ${ }^{63}$ compacted by ion implantation or ionizing radiation, ${ }^{64}$ or exhibiting higher fictive temperature by suitable heat-treatment. ${ }^{65}$ Fused silica irradiated by nanosecond laser pulses was found to exhibit redshifts in the inner core of the damaged sites, but blueshifts in the periphery of the damaged sites. ${ }^{66}$

In a study of structural modifications induced in silica glass by ion implantation and ionizing radiation, ${ }^{64}$ Devine argued that for the range $120^{\circ}<\theta<150^{\circ}$ the major cause of $v_{\mathrm{AS}}(\mathrm{Si}-\mathrm{O}-\mathrm{Si})$ variation is due to $\theta$ and not to changes in $\mathrm{k}_{\mathrm{s}}$ or $\mathrm{k}_{\mathrm{b}}$, Eq. (2). This is in agreement with studies of silica glass by molecular dynamics simulations ${ }^{67,68}$ which found an almost negligible change of the $\mathrm{Si}-\mathrm{O}$ bond length and intratetrahedral O-Si-O bond angle with pressure. On the contrary, the most pronounced change was in the inter-tetrahedral Si$\mathrm{O}-\mathrm{Si}$ angle, which decreases from $156^{\circ}$ to $136^{\circ}$ as pressure increases from -20 to $20 \mathrm{GPa}$. Therefore, in the following we may neglect possible variations in force constants and use Eq. (2) to estimate the average $\mathrm{Si}-\mathrm{O}-\mathrm{Si}$ bond angles $(\theta)$ in ULE 


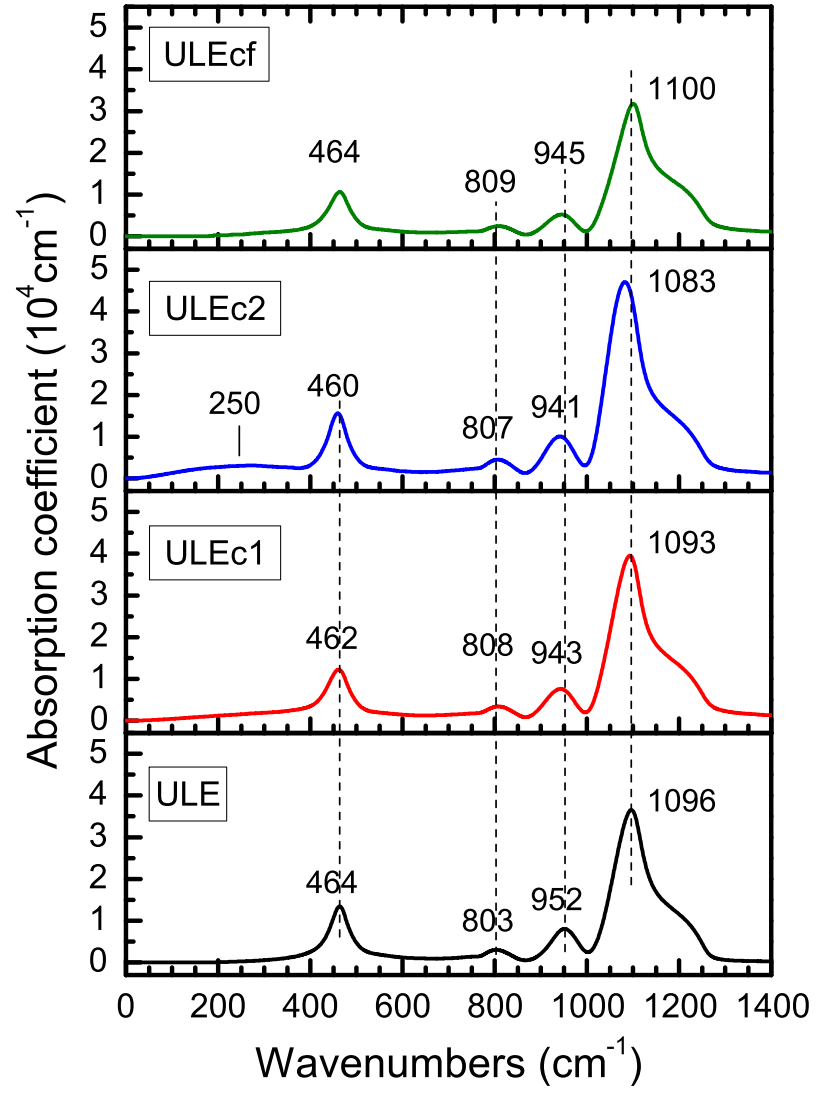

FIG. 11. IR absorption coefficient spectra of pristine ULE glass and the laser-processed ULE glasses (ULEc1, ULEc2, and ULEcf), as obtained by Kramers-Krönig transformation of the corresponding reflectance spectra shown in Fig. 10.

glasses on the basis of the measured $v_{\mathrm{AS}}(\mathrm{Si}-\mathrm{O}-\mathrm{Si})$ peak frequencies from the absorption spectra. The estimated values of $\theta$ are given in Table III with $\theta=2 \arcsin (\sin (\theta / 2))$, where the value of $\sin (\theta / 2)$ was obtained from the following expression derived from Eq. (2):

$$
\sin \frac{\theta}{2}=\sqrt{\left[\frac{\left(2 \pi c \nu_{A S}\right)^{2} \mathrm{~m}_{\mathrm{O}}}{2}-\mathrm{k}_{\mathrm{b}}\right] /\left(\mathrm{k}_{\mathrm{s}}-\mathrm{k}_{\mathrm{b}}\right) .}
$$

In Eq. (5), we employ $\mathrm{k}_{\mathrm{s}}=615.7 \mathrm{~N} / \mathrm{m}$ and $\mathrm{k}_{\mathrm{b}}=103.2 \mathrm{~N} / \mathrm{m}$ as discussed above. Figure 5 and Table III show that laser treatment appears to affect the silicate network through changes in the average $\mathrm{Si}-\mathrm{O}-\mathrm{Si}$ bond angle. With reference to silica glass, the average $\theta$ shifts by $-2.2^{\circ}$ and $-6.0^{\circ}$ in ULEc 1 and ULEc2, respectively, and by $+0.4^{\circ}$ in ULEcf.

According to Devine, ${ }^{64}$ the dependence of the $v_{\mathrm{AS}}(\mathrm{Si}-\mathrm{O}-$ $\mathrm{Si}$ ) frequency on the $\mathrm{Si}-\mathrm{O}-\mathrm{Si}$ bond angle reflects variations in glass density and for permanently densified silica glass, it takes the form

$$
\nu_{A S}=1301.2-91 \rho,
$$

where $\rho$ is the density (in $\mathrm{g} / \mathrm{cm}^{3}$ ) and $v_{\mathrm{AS}}$ is the infrared frequency (in $\mathrm{cm}^{-1}$ ) measured from absorption spectra. Assuming that Eq. (6) holds also for the silicate network in ULE glasses, we use the above expression to convert the infrared $v_{\text {AS }}$ data into density change $\Delta \rho / \rho_{0}$ of the silicate network relative to silica, where $\rho_{0}$ is the density of silica glass. The results in Fig. 12 show a linear correlation $\left(\mathrm{R}^{2}=0.999\right)$ between $\Delta \rho / \rho_{0}$ and the average $\theta$ in ULE glasses

$$
\frac{\Delta \rho}{\rho_{0}}=190.7-1.3 \theta .
$$

The reduction of $\theta$ results in increased density relative to silica glass by $2.7 \%$ for ULEc1 and $7.9 \%$ for ULEc2. The opposite holds for ULEcf where the increased average $\theta$ in the IR-probed area corresponds to density reduction by $0.5 \%$ with respect to silica glass.

Rouxel et al. ${ }^{69}$ have reported that the density of silica glass can increase permanently by as much as $21 \%$ when the pressure increases to $\sim 25 \mathrm{GPa}$. Generally, the dependence of $\Delta \rho / \rho_{0}$ on pressure shows a sigmoidal behavior in glasses and is empirically described by the function

$$
\frac{\Delta \rho}{\rho_{0}}=\frac{\alpha}{1+\beta \exp \left(-\mathrm{P} / \mathrm{P}_{0}\right)}-\frac{\alpha}{1+\beta},
$$

where $\mathrm{P}$ is the pressure and the fitting parameters $\alpha, \beta$, and $\mathrm{P}_{0}$ are glass-dependent, and for silica take the values $\alpha=21$, $\beta=5000$, and $\mathrm{P}_{0}=1.67 \mathrm{GPa}^{69}$ Assuming that Eq. (8) can be applied also to ULE glasses, the present IR data expressed by $\Delta \rho / \rho_{0}$ indicate that the average local pressure induced by fs laser irradiation reached values of 10.6 and $12.9 \mathrm{GPa}$ for the IR-probed areas in ULEc1 and ULEc2, such pressures causing densification by $\Delta \rho / \rho_{0}=2.7 \%$ and $7.9 \%$, respectively. Such densified regions should correspond mainly to

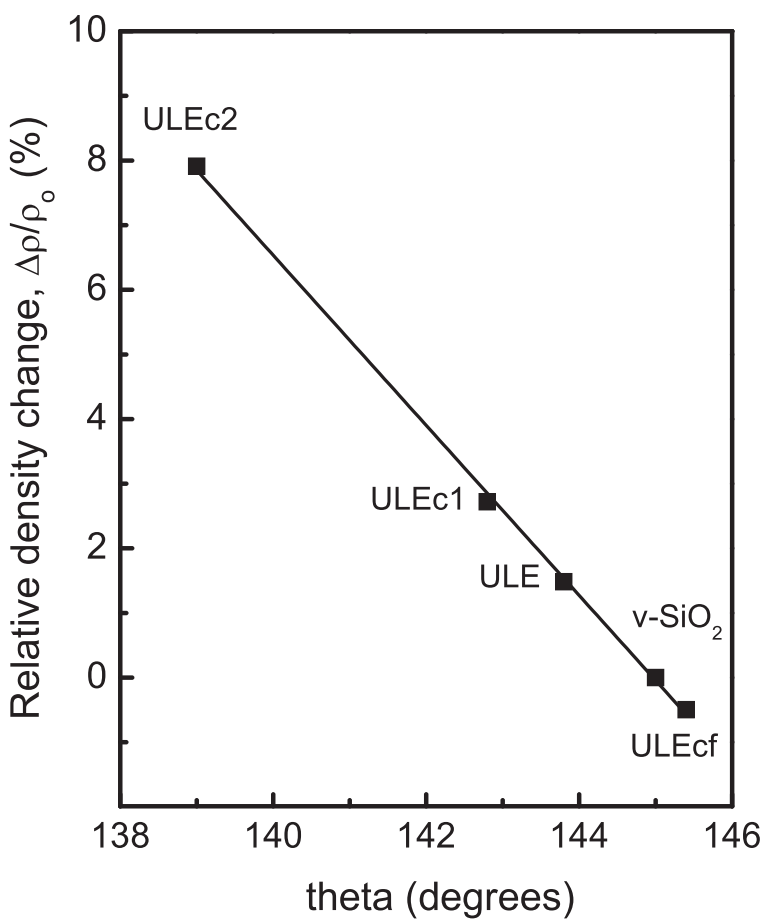

FIG. 12. Density change relative to silica glass, $\Delta \rho / \rho_{0}$, as a function of the inter-tetrahedral $\mathrm{Si}-\mathrm{O}-\mathrm{Si}$ bond angle, $\theta$, for pristine ULE glass and for the probed areas in fs laser irradiated ULE glasses (ULEc1, ULEc2, and ULEcf). The line is a least-square fit to the data. 
shells of the cavities containing molecular oxygen, which are present in the IR-probed areas of ULEc1 and ULEc2 (see Fig. 1). The result for ULEcf, $\Delta \rho / \rho_{0}=-0.5 \%$, suggests the presence of regions under tensile strain; these volumeexpanded regions should surround densified domains, i.e., the cavity shells which were removed by polishing in ULEcf (Fig. 1). It is to be noted, however, that such scaling can be performed only tentatively because of the large scatter in the fitting parameters $\alpha, \beta$, and $\mathrm{P}_{0}$, resulting from the large scatter in compaction data for intermediate pressures.

\section{Connectivity variations of the glass network in laser-processed ULE glasses}

As found above, laser-treatment of ULE glasses causes variations in the average local density in the order ULEcf $<\mathrm{ULE}<\mathrm{ULEc} 1<\mathrm{ULEc} 2$ for the IR-probed areas (Fig. 12). We explore here whether this trend is related to variations in silicate network connectivity, by measuring the transverseoptical (TO) and longitudinal-optical (LO) responses of the $v_{\mathrm{AS}}(\mathrm{Si}-\mathrm{O}-\mathrm{Si})$ mode, as this mode shows large LO-TO splitting due to long-range Coulomb interactions. ${ }^{22}$ An IR study of sol-gel silica glasses showed that the LO-TO splitting increases with the temperature of heat-treatment of gels. ${ }^{38}$ This effect was attributed to increasing silicate network connectivity through formation of additional $\equiv \mathrm{Si}-\mathrm{O}$-Si $\equiv$ bridging bonds, which in turn strengthens long-range Coulomb interactions. In this context, we consider here LO-TO splitting in ULE glasses and examine its dependence on laser treatment. The TO spectra correspond to the imaginary part, $\varepsilon_{2}(\nu)$, of the complex dielectric function, $\varepsilon^{*}(\nu)$, and the LO spectra to the energy loss function defined by $\operatorname{Im}\left(-\frac{1}{\varepsilon^{*}(\nu)}\right)$ $=\frac{\varepsilon_{2}(\nu)}{\varepsilon_{1}^{2}(\nu)+\varepsilon_{2}^{2}(\nu)}$, where $\varepsilon_{1}(\nu)$ is the real part of $\varepsilon^{*}(\nu){ }^{70}$

TO and LO spectra in the region of the $v_{\mathrm{AS}}(\mathrm{Si}-\mathrm{O}-\mathrm{Si})$ mode are depicted in the right column of Fig. 13, and show increased LO-TO splitting for ULEc1 and ULEc2 and decreased for ULEcf compared to pristine ULE. In fact, LOTO splitting for $v_{\mathrm{AS}}(\mathrm{Si}-\mathrm{O}-\mathrm{Si})$ is found to vary linearly with densification, $\Delta \rho / \rho_{0}$ (Fig. 14). We note that silica glass does not fit in the ULE trend, and this may reflect the absence of $\mathrm{TiO}_{4}$ tetrahedra from the matrix of silica glass. TO and LO spectra for $\mathrm{v}_{\mathrm{B}}(\mathrm{Si}-\mathrm{O}-\mathrm{Si})$ and $v_{\mathrm{as}}\left(\mathrm{TiO}_{4}\right)$ at ca. 805 and $950 \mathrm{~cm}^{-1}$, respectively, are shown also in Fig. 13 (left column). Despite the fact that these modes have smaller LO-TO splitting compared to $v_{\mathrm{AS}}(\mathrm{Si}-\mathrm{O}-\mathrm{Si})$, an increase in the splitting is observed from ULEcf to ULEc2 (Table III). Therefore, laser-treatment appears to enhance silicate network connectivity/density in the probed areas of ULEc1 and ULEc2 but not for ULEcf.

\section{Mechanisms of structure transformations by laser processing of ULE glass}

As discussed earlier ${ }^{71,72}$ and in more recent studies ${ }^{11-18,50-53,73}$ on laser-matter interactions and related applications, irradiation of glass with fs laser at high repetition rates results in multiphoton absorption and heat accumulation from the successive pulses. This leads to very high temperatures in the focal region and consequently to glass

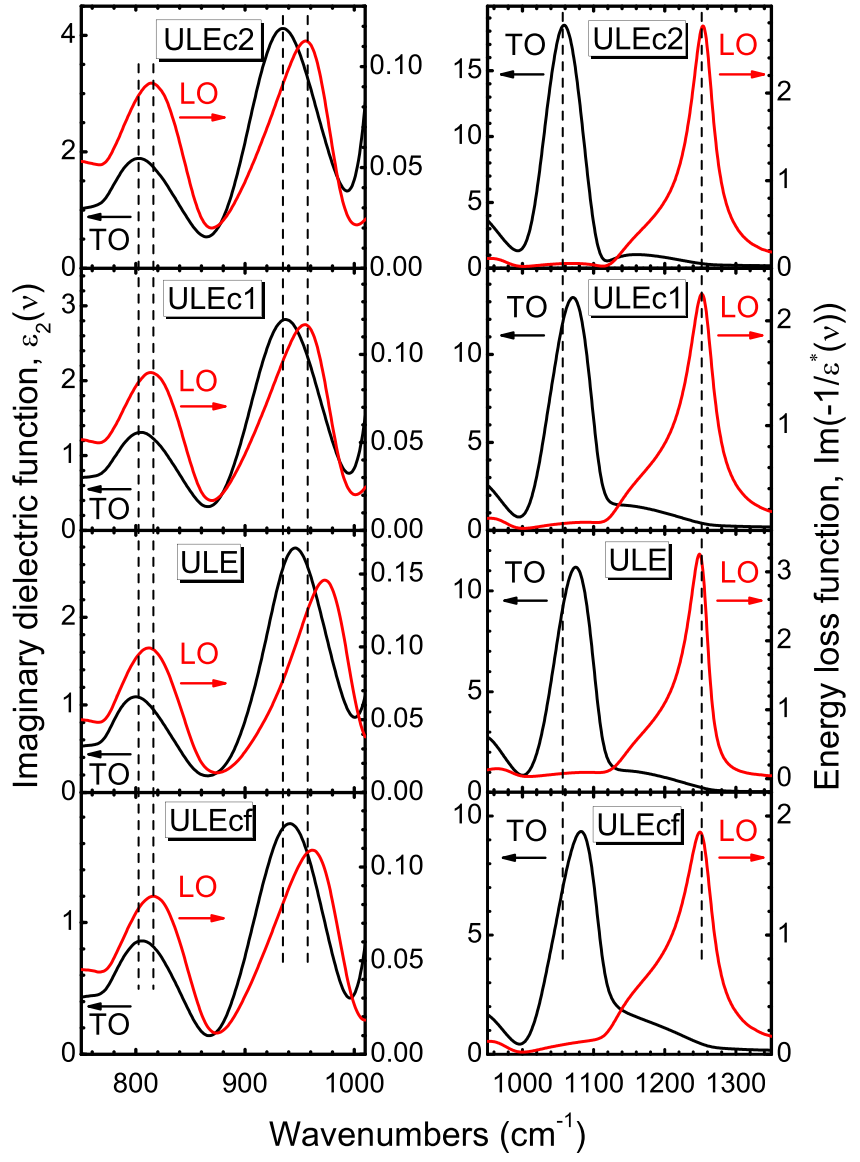

FIG. 13. Spectra of the imaginary part of the complex dielectric function (TO) and of the energy loss function (LO) for pristine ULE glass and for the probed areas of laser-processed ULE glasses (ULEc1, ULEc2, and ULEcf). The left column presents the spectra corresponding to the $\mathrm{v}_{\mathrm{B}}(\mathrm{Si}-\mathrm{O}-\mathrm{Si})$ and $v_{\text {as }}\left(\mathrm{TiO}_{4}\right)$ modes at ca. 805 and $950 \mathrm{~cm}^{-1}$, respectively, and the right column the spectra for the $v_{\mathrm{AS}}(\mathrm{Si}-\mathrm{O}-\mathrm{Si})$ mode. Spectra were arranged in the decreasing order of LO-TO splitting from top to bottom.

melting. Because of the large temperature difference between the focal volume and the surrounding material, the molten material cools rapidly after irradiation and quenches to a glass characterized by high fictive temperature. Depending on the laser irradiation parameters and the type of glass, the radiation-exposed region of glass may develop cavities with molecular oxygen. The Raman and IR results presented here showed that fs laser irradiation causes various types of microstructural changes with respect to pristine ULE glass; these spectral/structural changes were found to depend on the probed volume of the modified glass. Polishing after laser irradiation allowed spectroscopic probing of different areas of the modified glass. The exposed regions in ULEc1 and ULEc2 samples comprise mainly cavities and the molten and re-solidified material between cavities. On the other hand, the probed volume in ULEcf contains only laser-molten and re-solidified material below cavities, as the latter were removed by polishing.

The Raman and infrared results presented here, in combination with the earlier ESR study, ${ }^{12}$ can be expressed by the following reaction for the laser-molten and re-solidified glass around and below cavities (ULEcf): 


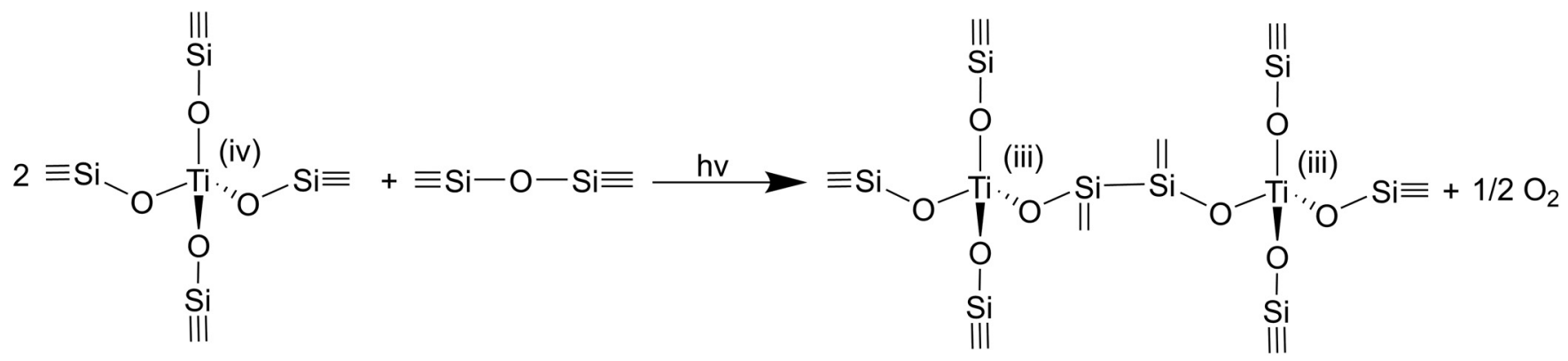

It is noted that Eq. (9) is mass-balanced considering that each $\mathrm{Si}$ atom in the configuration $\equiv \mathrm{Si}$-O- contributes by $1 / 4$ to the unit it belongs to, since the three bonds noted as $\equiv \mathrm{Si}$ belong to three other connected units. Likewise, each $\mathrm{Si}$ atom in the configuration $-\mathrm{O}-(=) \mathrm{Si}-\mathrm{Si}(=)-\mathrm{O}$ - contributes by $1 / 2$ to the unit. In the proposed scheme, the laser-induced photo-reduction of $\mathrm{Ti}^{4+}$ [noted as $\mathrm{Ti}^{(\mathrm{iv})}$ ] to $\mathrm{Ti}^{3+}$ [noted as $\left.\mathrm{Ti}^{\text {(iii)}}\right]$ leads to the formation of "isolated" $\mathrm{TiO}_{4}$ tetrahedra with titanium in the $\mathrm{Ti}^{3+}$ oxidation state, and molecular oxygen. This process requires destruction of one $\equiv \mathrm{Si}-\mathrm{O}-\mathrm{Si} \equiv$ bridging bond per two $\mathrm{Ti}$ ions and the formation of one $\equiv \mathrm{Si}$ $\mathrm{Si} \equiv$ bond connecting the two $\mathrm{TiO}_{4}$ tetrahedra. The evolved molecular oxygen is trapped in cavities, which were removed from the probed volume in ULEcf by polishing. The $\equiv \mathrm{Si}-$
$\mathrm{Si} \equiv$ bond is a known diamagnetic defect in silica glass, also called the oxygen deficiency center, found to form under $\gamma$ irradiation of silica glass or in unirradiated oxygen-deficient silica, and absorbs in the vacuum-ultraviolet region at $7.6 \mathrm{eV} .{ }^{74-76}$ Detection of $\equiv \mathrm{Si}-\mathrm{Si} \equiv$ bond formation in irradiated ULE glasses by Raman spectroscopy is rather difficult as the stretching vibration of this bond would be active at ca. $420-430 \mathrm{~cm}^{-1}, 77$ i.e., in the region dominated by the strongest silicate band due to symmetric stretching-bending vibration of Si-O-Si bridges in large arrangements of $\mathrm{SiO}_{4}$ tetrahedra [Fig. 3(b)].

The spectroscopic results for the laser-written areas which contain shells of cavities (samples ULEc1 and ULEc2) can be expressed as follows:

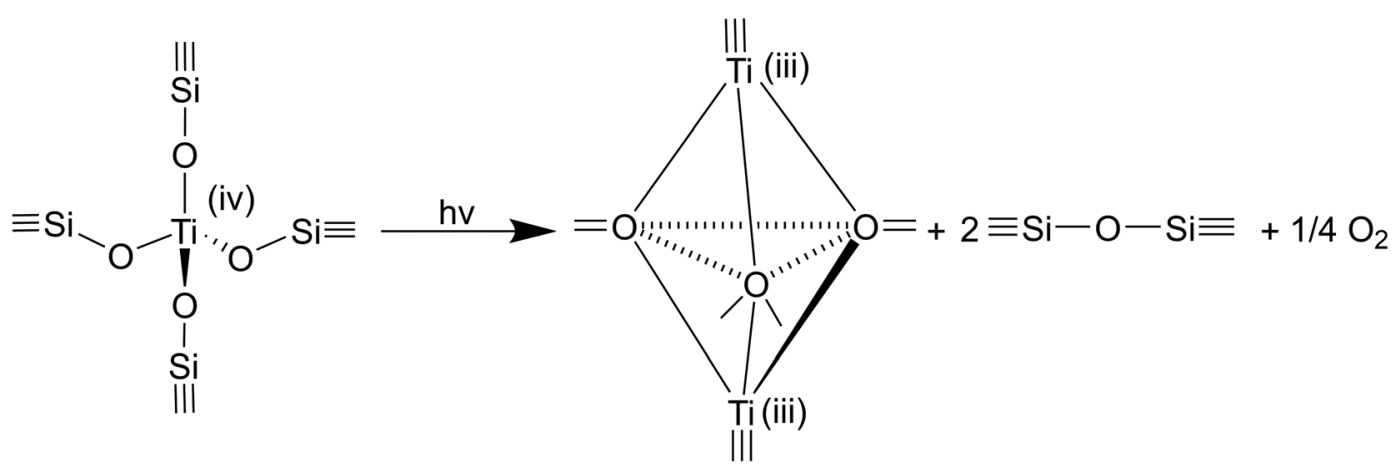

In this case, the photo-reduction of $\mathrm{Ti}^{4+}$ to $\mathrm{Ti}^{3+}$ leads to formation of $\mathrm{Ti}_{2} \mathrm{O}_{3}$-type clusters, where $\mathrm{Ti}^{3+}$ ions are sixfold coordinated to oxygen. In such $\mathrm{Ti}_{2} \mathrm{O}_{3}$-type clusters, each $\mathrm{Ti}-\mathrm{O}$ octahedron shares one face and three edges with other Ti-O octahedral units, with oxygen being coordinated by four Ti ions. ${ }^{78}$ Therefore, each oxygen atom contributes by $1 / 2$ (i.e., $2 / 4$ ) and each Ti atom also by $1 / 2$ (i.e., $3 / 6$ ) to the Ti-O octahedral unit shown in scheme (10). This process leads to the evolution of molecular oxygen which is trapped in cavities as detected by Raman spectroscopy, and to the creation of additional homopolar $\equiv \mathrm{Si}-\mathrm{O}-\mathrm{Si} \equiv$ bonds at the expense of Ti-O-Si bonds. $\mathrm{Ti}_{2} \mathrm{O}_{3}$ has been reported to form upon electron beam-irradiation of $\mathrm{TiO}_{2}$ as a result of reduction of $\mathrm{Ti}^{4+}$ to $\mathrm{Ti}^{3+}, 79,80$ and also to constitute the disordered surface shell of crystalline black $\mathrm{TiO}_{2}$ synthesized by pulsed laser vaporization. ${ }^{62}$
Regarding the fs laser-induced changes in the silicate network, Eq. (9) predicts that the molten and re-solidified glass should have a lower silicate network connectivity because of the reduction of the $\equiv \mathrm{Si}-\mathrm{O}-\mathrm{Si} \equiv$ bridge population. The opposite is expected for the shells of cavities according to Eq. (10), where the creation of additional $\equiv \mathrm{Si}$ $\mathrm{O}-\mathrm{Si} \equiv$ bonds would lead to increased silicate network connectivity. Such differences in silicate connectivity between ULEcf on one hand and ULEc1/ULEc2 on the other, in terms of Eqs. (9) and (10), are in full agreement with the LO-TO splitting of the $v_{\mathrm{AS}}(\mathrm{Si}-\mathrm{O}-\mathrm{Si})$ mode and the densification $\Delta \rho / \rho_{0}$ found for these laser-treated glasses (Fig. 14).

The results of this work are schematically summarized in Fig. 15, where the laser-modified region inside the ULE glass is depicted by a reverse teardrop-like structure inscribed by fs laser irradiation (incident from the top). Glass darkening is 


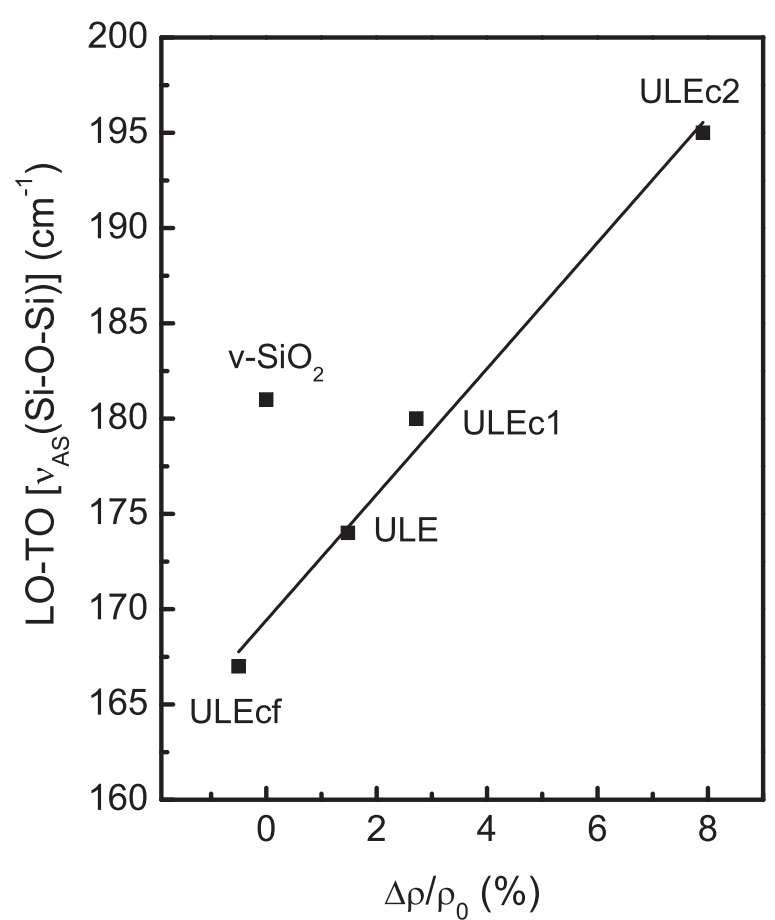

FIG. 14. Correlation between the LO-TO splitting of the $v_{\mathrm{AS}}(\mathrm{Si}-\mathrm{O}-\mathrm{Si})$ mode and the density change relative to silica glass, $\Delta \rho / \rho_{0}$, for pristine ULE and for the IR-probed areas of fs laser irradiated ULE glasses (ULEc1, ULEc2, and ULEcf). The line is a least-square fit to the ULE data.

caused by photoreduction of $\mathrm{Ti}^{4+}$ to $\mathrm{Ti}^{3+}$ in the laserirradiated region. The cavity containing molecular oxygen is formed in the upper part of the teardrop-like structure, and has a shell of compacted glass with trivalent titanium ions in octahedral sites which aggregate to form amorphous $\mathrm{Ti}_{2} \mathrm{O}_{3}$ clusters. The modified material surrounding the cavity consists of laser-molten and resolidified glass, which has lower density than pristine ULE and contains trivalent titanium ions in tetrahedral sites dispersed in the silicate network.

\section{CONCLUSIONS}

We studied the pristine ultra-low expansion (ULE) glass by X-ray diffraction, micro-Raman and IR spectroscopy, as
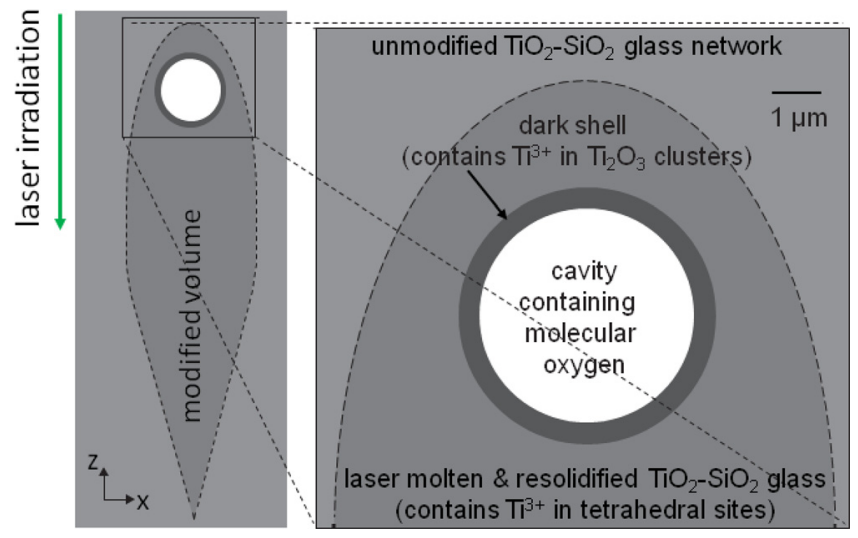

FIG. 15. Sketch of the laser-modified region in ULE glass. Irradiation with multiple laser pulses at high repetition rates causes melting and subsequent resolidification of the glassy material. A cavity is formed in the upper part of the modified region, having a shell of compacted glass and containing molecular oxygen. The cavity is surrounded by a material of lower density. Darkening after laser irradiation is caused by photoreduction of $\mathrm{Ti}^{4+}$ to $\mathrm{Ti}^{3+}$. this binary titanosilicate glass with $5.67 \mathrm{~mol} . \% \mathrm{TiO}_{2}$ attracts lately interest for inscribing nanogratings by fs laser processing. Titanium was found predominantly in tetrahedral sites which are highly dispersed in the silicate matrix of ULE. XRD and Raman experiments showed also the presence of sixfold coordinated $\mathrm{Ti}^{4+}$ sites, estimated to be less than $5 \%$. In addition, the symmetric stretching vibration of the $\mathrm{TiO}_{4}$ tetrahedral units, $v_{\mathrm{s}}\left(\mathrm{TiO}_{4}\right)$, at $1107 \mathrm{~cm}^{-1}$ showed resonance Raman intensity enhancement upon excitation with UV light $(325 \mathrm{~nm})$. The effect was attributed to the $v_{\mathrm{s}}\left(\mathrm{TiO}_{4}\right)$ coupling with the $\mathrm{O}^{2-} \rightarrow \mathrm{Ti}^{4+}$ charge-transfer band at ca. $200 \mathrm{~nm}$.

For the fs laser-modified ULE glass, optical imaging showed the formation of cavities of $4-6 \mu \mathrm{m}$ in diameter in the laser irradiated areas, while the spatial resolution of microRaman spectroscopy allowed the mapping of structural variations over $80 \mu \mathrm{m} \times 30 \mu \mathrm{m}$ laser-modified areas. Key findings on the effects of laser irradiation include: (a) increased population of 3-membered silicate rings, (b) formation of molecular oxygen only in cavities, and (c) reduced frequency and increased bandwidth of the $\mathrm{TiO}_{4}$-related modes over the lasermodified areas. The combined Raman and IR reflectance results indicate the formation of $\mathrm{Ti}^{3+}$ octahedral sites aggregated in amorphous $\mathrm{Ti}_{2} \mathrm{O}_{3}$-type clusters in the shells of cavities, while the glassy material surrounding these cavities contains $\mathrm{Ti}^{3+}$ in tetrahedral sites dispersed in the silicate network.

Laser irradiation of ULE was found to cause also restructuring of the silicate network, as probed mainly by IR spectroscopy. Consideration of the strong asymmetric stretching mode of $\mathrm{Si}-\mathrm{O}-\mathrm{Si}$ bridges, $v_{\mathrm{AS}}(\mathrm{Si}-\mathrm{O}-\mathrm{Si})$ at ca. $1080-1100 \mathrm{~cm}^{-1}$, showed that the average $\mathrm{Si}-\mathrm{O}-\mathrm{Si}$ bond angle $(\theta)$ changes in the laser-modified areas of ULE. It decreases by as much as $\Delta \theta=6.0^{\circ}$ with respect to $\mathrm{v}-\mathrm{SiO}_{2}$ in IR-probed areas containing shells of cavities, and increases by $\Delta \theta=0.4^{\circ}$ in the lasermolten and re-solidified materials surrounding the cavities. Changes in $\theta$ reflect local density variations induced by laser irradiation, reaching up to about $8 \%$ densification relative to silica glass in the shells of cavities and $0.5 \%$ reduction of density in the surrounding material.

The effects of laser irradiation on ULE were described by chemical reactions, Eqs. (9) and (10), which account for (i) the reduction of $\mathrm{Ti}^{4+}$ to $\mathrm{Ti}^{3+}$, (ii) the formation of $\mathrm{Ti}^{3+}$ "isolated" tetrahedral sites and aggregated octahedral sites in the surrounding material and in the shells of cavities, respectively, and together with (iii) the restructuring of the silicate network. The silicate restructuring leads to enhanced silicate connectivity in the shells of cavities, and to decreased connectivity in the cavities' surrounding glassy material, as confirmed by measuring the LO-TO splitting for the $v_{\mathrm{AS}}(\mathrm{Si}-$ $\mathrm{O}-\mathrm{Si}$ ) mode in the corresponding modified areas of laserprocessed ULE glasses.

\section{ACKNOWLEDGMENTS}

We acknowledge partial support of this work by the German-Greek program DAAD-IKYDA 2015 for the promotion of scientific cooperation between Greece and Germany. Helpful discussions with Professor Dr. Dominique de Ligny, Universität Erlangen-Nürnberg, Germany, are gratefully acknowledged. 
${ }^{1}$ P. C. Shultz and H. T. Smyth, in Amorphous Materials, edited by R. W. Douglas and B. Ellis (Wiley-Interscience, New York, 1970), pp. 453-461.

${ }^{2}$ S. Chao, W.-H. Wang, and C.-C. Lee, Appl. Opt. 40, 2177 (2001).

${ }^{3}$ R. J. Davis and Z. Liu, Chem. Mater. 9, 2311 (1997).

${ }^{4}$ A. Keshavaraja, V. Ramaswamy, H. S. Soni, A. V. Ramaswamy, and P. Ratnasamy, J. Catal. 157, 501 (1995).

${ }^{5}$ D. R. Sandstrom, F. W. Lytle, P. S. P. Wei, R. B. Greegor, J. Wong, and P. Schultz, J. Non-Cryst. Solids 41, 201 (1980).

${ }^{6}$ R. B. Greegor, F. W. Lytle, D. R. Sandstrom, J. Wong, and P. Schultz, J. Non-Cryst. Solids 55, 27 (1983).

${ }^{7}$ H. Hanada, T. Aikawa, and N. Soga, J. Am. Ceram. Soc. 67, 52 (1984).

${ }^{8}$ M. Emili, L. Incoccia, S. Mobilio, G. Fagherazzi, and M. Guglielmi, J. Non-Cryst. Solids 74, 129 (1985).

${ }^{9}$ H. Yamashita, S. Kawasaki, Y. Ichihashi, M. Harada, M. Takeuchi, M. Anpo, G. Stewart, M. A. Fox, C. Louis, and M. Che, J. Phys. Chem. B 102, 5870 (1998).

${ }^{10}$ D. Gerlich, M. Wolf, I. Yaacov, and B. Nissenson, J. Non-Cryst. Solids 21, 243 (1976); ULE ${ }^{\circledR}$ Corning Code 7972 Brochure (Corning Advanced Optics, Canton, New York, 2016); available at https://www.corning.com/media/ worldwide/csm/documents/7972\%20ULE\%20Product\%20Information\% 20Jan\%202016.pdf

${ }^{11}$ S. Richter, C. Miese, S. Doring, F. Zimmermann, M. J. Withford, A. Tünnermann, and S. Nolte, Opt. Mater. Express 3, 1161 (2013).

${ }^{12}$ S. Richter, D. Möncke, F. Zimmermann, E. I. Kamitsos, L. Wondraczek, A. Tünnermann, and S. Nolte, Opt. Mater. Express 5, 1834 (2015).

${ }^{13}$ L. P. R. Ramirez, M. Heinrich, S. Richter, F. Dreisow, R. Keil, A. V. Korovin, U. Peschel, S. Nolte, and A. Tünnermann, Appl. Phys. A 100, 1 (2010).

${ }^{14}$ M. Beresna, M. Gecevičius, and P. G. Kazansky, Opt. Mater. Express 1, 783 (2011).

${ }^{15}$ H. Zheng and C. L. Gnian, Opt. Lasers Eng. 41, 791 (2004).

${ }^{16}$ S. Richter, F. Zimmermann, S. Doring, A. Tünnermann, and S. Nolte, Appl. Phys. A 110, 9 (2013).

${ }^{17}$ K. Cvecek, I. Miyamoto, and M. Schmidt, Opt. Express 22, 15877 (2014).

${ }^{18}$ S. Richter, F. Zimmermann, R. Eberhardt, A. Tünnermann, and S. Nolte, Appl. Phys. A 121, 1 (2015).

${ }^{19}$ D. Palles, I. Konidakis, C. P. E. Varsamis, and E. I. Kamitsos, RSC Adv. 6, 16697 (2016)

${ }^{20}$ G. S. Henderson and M. E. Fleet, J. Non-Cryst. Solids 211, 214 (1997).

${ }^{21}$ T. Furukawa, K. E. Fox, and W. B. White, J. Chem. Phys. 75, 3226 (1981).

${ }^{22}$ F. L. Galeener, A. J. Leadbetter, and M. W. Stringfellow, Phys. Rev. B 27, 1052 (1983); F. L. Galeener, Phys. Rev. B 19, 4292 (1979); F. L. Galeener, Solid State Commun. 44, 1037 (1982).

${ }^{23}$ A. Pasquarello and R. Car, Phys. Rev. Lett. 80, 5145 (1998).

${ }^{24}$ D. Kato, J. Appl. Phys. 47, 2050 (1976).

${ }^{25}$ H. R. Chandrasekhar, M. Chandrasekhar, and M. H. Manghnani, J. NonCryst. Solids 40, 567 (1980).

${ }^{26}$ P. P. Bihuniak and R. A. Condrate, J. Non-Cryst. Solids 44, 331 (1981); M. F. Best and R. A. Condrate, J. Mater. Sci. Lett. 4, 994 (1985).

${ }^{27}$ D. S. Knight, C. G. Pantano, and W. B. White, Mater. Lett. 8, 156 (1989).

${ }^{28}$ A. Chmel, G. M. Eranosyan, and A. A. Kharshak, J. Non-Cryst. Solids 146, 213 (1992)

${ }^{29}$ G. S. Henderson and M. E. Fleet, Can. Miner. 33, 399 (1995); available at http://canmin.geoscienceworld.org/content/33/2/399.

${ }^{30}$ E. I. Kamitsos and W. M. Risen, J. Non-Cryst. Solids 65, 333 (1984).

${ }^{31}$ V. Dimitrov and S. Sakka, J. Appl. Phys. 79, 1736 (1996).

${ }^{32}$ J. Su, G. Xiong, J. Zhou, W. Liu, D. Zhou, G. Wang, X. Wang, and H. Guo, J. Catal. 288, 1 (2012).

${ }^{33}$ L. Escobar-Alarcón, J. Pérez-Álvarez, D. Solís-Casados, E. Camps, S. Romero, and J. Jiménez-Becerril, Appl. Phys. A 110, 909 (2013).

${ }^{34}$ C. F. Smith, R. A. Condrate, and W. E. Votava, Appl. Spectrosc. 29, 79 (1975).

${ }^{35}$ D. Y. Smith, C. E. Black, C. C. Homes, and E. Shiles, Phys. Status Solidi C 4, 838 (2007).

${ }^{36}$ P. G. Pai, S. S. Chao, Y. Takagi, and G. Lucovsky, J. Vac. Sci. Technol., A 4, 689 (1986).

${ }^{37}$ C. T. Kirk, Phys. Rev. B 38, 1255 (1988).

${ }^{38}$ E. I. Kamitsos, A. P. Patsis, and G. Kordas, Phys. Rev. B 48, 12499 (1993); E. I. Kamitsos, Phys. Rev. B 53, 14659 (1996).

${ }^{39}$ A. Lehmann, L. Schumann, and K. Hubner, Phys. Status Solidi B 117, 689 (1983).

${ }^{40}$ R. L. Mozzi and B. E. Warren, J. Appl. Cryst. 2, 164 (1969).

${ }^{41}$ R. Dupree and R. Pettifer, Nature 308, 523 (1984).

${ }^{42}$ C. J. Brinker, R. J. Kirkpatrick, D. R. Tallant, B. C. Bunker, and B. Montez, J. Non-Cryst. Solids 99, 418 (1988).

${ }^{43}$ M. Kumar, A. Uniyal, A. P. S. Chauhan, and S. P. Singh, Bull. Mater. Sci. 26, 335 (2003).
${ }^{44}$ K. Yano and Y. Morimoto, J. Non-Cryst. Solids 349, 120 (2004).

${ }^{45}$ G. Ricchiardi, A. Damin, S. Bordiga, C. Lamberti, G. Spano, F. Rivetti, and A. Zecchina, J. Am. Chem. Soc. 123, 11409 (2001).

${ }^{46}$ S. Bordiga, A. Damin, F. Bonino, G. Ricchiardi, A. Zecchina, R. Tagliapietra, and C. Lamberti, Phys. Chem. Chem. Phys. 5, 4390 (2003).

${ }^{47}$ A. Schütz, D. Ehrt, M. Dubiel, X. Yang, B. Mosel, and H. Eckert, Glass Sci. Technol. 77, 295 (2004); X. C. Yang, M. Dubiel, D. Ehrt, and A. Schütz, J. Non-Cryst. Solids 354, 1172 (2008).

${ }^{48}$ G. Guimbretiere, M. Dussauze, and E. I. Kamitsos, Appl. Phys. Lett. 97, 171103 (2010).

${ }^{49}$ L. Bressel, D. de Ligny, E. G. Gamaly, A. V. Rode, and S. Juodkazis, Opt. Express 1, 1150 (2011).

${ }^{50}$ A. Kubota, M.-J. Caturla, J. S. Stölken, and M. D. Feit, Opt. Express 8, 611 (2001).

${ }^{51}$ J. W. Chan, T. R. Huser, S. H. Risbud, and D. M. Krol, Appl. Phys. A 76, 367 (2003).

${ }^{52}$ D. M. Krol, J. W. Chan, T. R. Huser, S. H. Risbud, and J. S. Hayden, Proc. SPIE 5662, 30 (2004); D. M. Krol, J. Non-Cryst. Solids 354, 416 (2008).

${ }^{53}$ N. Varkentina, M. Dussauze, A. Royon, M. Ramme, Y. Petit, and L. Canioni, Opt. Mater. Express 6, 79 (2016).

${ }^{54}$ R. J. Hemley, H. K. Mao, P. M. Bell, and B. O. Mysen, Phys. Rev. Lett. 57, 747 (1986).

${ }^{55}$ T. Deschamps, A. Kassir-Bodon, C. Sonneville, J. Margueritat, C. Martinet, D. de Ligny, A. Mermet, and B. Champagnon, J. Phys.: Condens. Matter 25, 025402 (2013)

${ }^{56}$ A. Cornet, V. Martinez, D. de Ligny, B. Champagnon, and C. Martinet, J. Chem. Phys. 146, 094504 (2017).

${ }^{57}$ H. Sugiura, R. Ikeda, K. Kondo, and T. Yamadaya, J. Appl. Phys. 81, 1651 (1997)

${ }^{58}$ A. Winterstein-Beckmann, D. Möncke, P. Palles, E. I. Kamitsos, and L. Wondraczek, J. Non-Cryst. Solids 405, 196 (2014).

${ }^{59} \mathrm{~K}$. Nakamoto, Infrared and Raman Spectra of Inorganic and Coordination Compounds (John Wiley and Sons, New York, 1978), pp. 142-143.

${ }^{60}$ M. Heili, B. Poumellec, E. Burov, C. Gonnet, C. le Losq, D. R. Neuville, and M. Lancry, J. Mater. Sci. 51, 1659 (2016).

${ }^{61}$ G. Lucovsky, R. J. Sladek, and J. W. Allen, Phys. Rev. B 16, 5452 (1977).

${ }^{62}$ M. Tian, M. Mahjouri-Samani, G. Eres, R. Sachan, M. Yoon, M. F. Chisholm, K. Wang, A. A. Puretzky, C. M. Rouleau, D. B. Geohegan, and G. Duscher, ACS Nano 9, 10482 (2015).

${ }^{63}$ J. Arndt and D. Stoffler, Phys. Chem. Glasses 10, 117 (1969).

${ }^{64}$ R. A. B. Devine, J. Non-Cryst. Solids 152, 50 (1993); R. A. B. Devine, Nucl. Instrum. Methods B 91, 378 (1994).

${ }^{65}$ M. Tomozawa, J.-W. Hong, and S.-R. Ryu, J. Non-Cryst. Solids 351, 1054 (2005).

${ }^{66}$ M. J. Matthews, C. W. Carr, and H. A. Bechtel, Appl. Phys. Lett. 99, 151109 (2011).

${ }^{67}$ L. Huang, L. Duffrene, and J. Kieffer, J. Non-Cryst. Solids 349, 1 (2004).

${ }^{68}$ L. Huang and J. Kieffer, Phys. Rev. B 69, 224204 (2004).

${ }^{69}$ T. Rouxel, H. Ji, T. Hammouda, and A. Moreac, Phys. Rev. Lett. 100, 225501 (2008).

${ }^{70}$ E. I. Kamitsos, "Infrared spectroscopy of glasses," in Modern Glass Characterization, edited by M. Affatigato (John Wiley \& Sons, Inc., 2015), Chap. 2, pp. 32-73.

${ }^{71}$ K. M. Davis, K. Miura, N. Sugimoto, and K. Hirao, Opt. Lett. 21, 1729 (1996); K. Miura, J. R. Qiu, H. Inouye, T. Mitsuyu, and K. Hirao, Appl. Phys. Lett. 71, 3329 (1997)

${ }^{72}$ E. N. Glezer, M. Milosavljevic, L. Huang, R. J. Finlay, T.-H. Her, J. P. Callan, and E. Mazur, Opt. Lett. 21, 2023 (1996); E. N. Glezer and E. Mazur, Appl. Phys. Lett. 71, 882 (1997).

${ }^{73}$ J. D. Musgraves, K. Richardson, and H. Jain, Opt. Mater. Express 1, 921 (2011).

${ }^{74}$ E. P. O'Reilly and J. Robertson, Phys. Rev. B 27, 3780 (1983).

${ }^{75}$ H. Hosono, Y. Abe, H. Imagawa, H. Imai, and K. Arai, Phys. Rev. B 44, 12043 (1991).

${ }^{76}$ L. Skuja, M. Hirano, H. Hosono, and K. Kajihara, Phys. Status Solidi C 2, 15 (2005).

${ }^{77}$ J. R. Durig and J. S. Church, J. Chem. Phys. 73, 4784 (1980).

${ }^{78}$ A. Wold and K. Dwight, Solid State Chemistry. Synthesis, Structure, and Properties of Selected Oxides and Sulfides (Chapman and Hall Inc., New York, 1993), pp. 111-112.

${ }^{79}$ P. Kern, Y. Müller, J. Patscheider, and J. Michler, J. Phys. Chem. B 110, 23660 (2006).

${ }^{80}$ M. Ohwada, K. Kimoto, K. Suenaga, Y. Sato, Y. Ebina, and T. Sasaki, J. Phys. Chem. Lett. 2, 1820 (2011). 